Research Article

\title{
Research on the Molding Design and Optimization of the Molding Process Parameters of the Automobile Trunk Trim Panel
}

\author{
Youmin Wang $(\mathbb{D}$, Zhaozhe Zhu $(\mathbb{D}$, Lingfeng Tang, and Qinshuai Jiang $(\mathbb{D}$ \\ School of Mechanical and Automotive Engineering, Anhui Polytechnic University, Wuhu, Anhui 241000, China \\ Correspondence should be addressed to Zhaozhe Zhu; 2190130110@stu.ahpu.edu.cn
}

Received 8 March 2020; Accepted 8 April 2020; Published 30 April 2020

Academic Editor: Fuat Kara

Copyright (c) 2020 Youmin Wang et al. This is an open access article distributed under the Creative Commons Attribution License, which permits unrestricted use, distribution, and reproduction in any medium, provided the original work is properly cited.

\begin{abstract}
In order to put forward the theoretical calculation formula for the compression force of the compression mold of the trunk trim panel, obtain the influence trend of the process parameters on the molding quality of the trunk trim panel, and obtain the optimal process parameters combination for the compression molding of the trunk trim panel, four process parameters, the heating temperature, time, compression pressure, and holding time, which affected the compression molding, were selected as the level factors; the maximum thinning rate, maximum thickening rate, and shrinkage rate of the trunk trim panel were selected as evaluation indicators and orthogonal experiments were designed and completed; the comprehensive weighted scoring method was used to obtain the comprehensive score results and obtain the comprehensive evaluation indicators of the best combination of process parameters of trunk trim panel; BP neural network and genetic algorithm were used to study the change trend of the evaluation indicators of trunk trim panel with the changes of process parameters; based on the optimal process parameter combination and the established neural network's prediction function, the maximum thinning rate, maximum thickening rate, and shrinkage rate under a single process parameter change could be predicted, and the influence of a single process parameter on the maximum thinning rate, maximum thickening rate, and shrinkage rate could be obtained; the process parameters were optimized, and a maximum thinning rate of $28 \%$, a maximum thickening rate of $4.3 \%$, and a shrinkage rate of $0.8 \%$ were obtained; the optimal molding process parameters of the trunk trim panel were heating temperature of $209^{\circ} \mathrm{C}$, heating time of $62 \mathrm{~s}$, molding pressure of $14 \mathrm{kPa}$, and holding pressure time of $49 \mathrm{~s}$; after optimization, the maximum shrinkage rate was $28.0880 \%$, the maximum thickening rate was $44.3264 \%$, and the shrinkage rate was $0.8901 \%$; according to the optimal process parameters, the quality of the trunk trim panel was very good, which met the production quality requirements.
\end{abstract}

\section{Introduction}

As the main processing method of automotive interior parts, compression molding has the advantages of high production efficiency, simple mold structure, and high product scale accuracy. Scholars at home and abroad have done a lot of theoretical experiments on the injection molding performance of plastic parts and various factors that affect the forming process. However, there are lacking research studies on compression molding of plastic parts, which leads to the backward design level of automotive interior molds. The molding process parameters are basically established by experience, which cannot guarantee the quality of interior products and cause waste of manpower and material resources. Therefore, how to solve the above problems has become the primary task of the interior industry. The purpose of this article is to ensure the lightweight materials in the vehicle and reduce the quality of the entire vehicle to achieve a lighter and stronger trunk trim panel by optimization. Therefore, the fuel consumption of the vehicle can also be reduced. Reducing fuel consumption is essential for reducing the consumption of fossil fuel [1]. Wang et al. [2] used Moldflow injection molding analysis function to complete the structural analysis of the moving mold and obtained a reasonable structural solution. The obtained temperature and pressure results were imported into ANSYS, and ANSYS was used to simulate the heating process of the molding and analyze the stress and strain conditions of the molding, but the optimal pressure and 
temperature combination have not been fully studied; the best molding process parameters cannot be obtained; orthogonal experiments have not been performed; and the data cannot be further verified. Xie et al. [3] carried out an orthogonal experiment to analyze the influence of the four process parameters of forming temperature, forming pressure, dwell time, and cooling rate on the performance of the sheet and determined the best forming process parameters, but the effect of heating time on compression molding was not analyzed and the obtained process parameters were not further optimized. Fujihara et al. [4] designed and completed orthogonal experiments in order to obtain the optimum forming process parameters of PEEK. The process parameters were heating temperature and heating time, which were taken at three levels. Although orthogonal experiments were completed, the effects of pressure and dwell time on compression molding were not considered. It can be obtained from the above references that most scholars have determined the process parameters of the composite material molding process through experiments but have not carried out related researches on the structural design of the compression molding and the optimization of the molding process parameters. Molding design is a vital part of product development and a key factor affecting product quality, production efficiency, and cost. In addition, the range of process parameter values is too large, and the results determined by only selecting points for experiments are not necessarily optimal process parameters. In order to obtain trunk trim panel with better molding quality, product parts and molds are designed, orthogonal experiments are designed, and algorithms are used to optimize them; then the optimal parameter combination of the trunk trim panel molding process can be obtained.

\section{Molding Design of Trunk Trim Panel}

Theoretical analyses of the compression molding of the trunk trim panel were performed, and the compression pressure was calculated. By determining the shrinkage of the trunk trim panel parts and the determination of the mold parting, the concave-convex mold, the material frame, guide mechanism, and mold bases were designed; the design and calculation of heat transfer of the cooling system were completed.

\subsection{Overall Structural Scheme of Compression Molding of the} Trunk Trim Panel. When the trunk trim panel was taken out of the concave-convex mold, it returned to room temperature. Liang et al. [5] show that the size of the trunk trim panel would shrink due to thermal expansion and contraction. According to the production summary, the shrinkage rate of the trunk trim panel was $1 \%$.

According to the requirements of the mold, concave and convex bodies of the trunk trim panel are created. The body was $1305 \mathrm{~mm}$ long, $648 \mathrm{~mm}$ wide, and $239 \mathrm{~mm}$ high. The direction adjusted automatically according to the direction of the demolding. The concave and convex mold entities were divided by the parting surface, and the parting surface was moved $25 \mathrm{~mm}$ up and down to cut the concave and convex mold entities to obtain a concave-convex mold with a thickness of $25 \mathrm{~mm}$.

Qin et al. [6] set the material pin and the material frame and prevented the sheet from wrinkling and instability during the molding process. The material pin penetrated the sheet and fixed the surroundings to avoid the trunk trim panel from wrinkling. Designing the material frame to match the material needle, the material frame was aligned up and down, which effectively dispersed the horizontal force of the sheet and also prevented the sheet from slipping out of the material needle, as shown in Figure 1.

The guide mechanism of the trunk trim panel included a guide post and a guide sleeve, which could make the molding process accurate, avoid wrong mold closing direction, prevent mold damage, and reduce side pressure. Due to large parts of this trunk trim panel and high precision requirements, four guide posts were selected, as shown in Figure 2.

Cai [7] shows that the trunk trim panel mold formwork was the skeleton of the entire mold. The structure of the concave-convex mold, cooling system, pressing device, guide mechanism, and other structures were fixed. In addition to the basic mechanism, the formwork should also reserve a place for structures such as car demolition holes and lifting rings and have corresponding mating mechanisms. The overall structure is shown in Figure 3.

\subsection{Calculation of the Pressure of the Compression Molding of} Trunk Trim Panel. In the past, the molding pressure obtained from the empirical formula was not accurate enough. In this paper, the theoretical formula was derived based on the thermoplastic power-law equations, which could obtain a more accurate molding pressure value. The trunk trim panel was in a softened state in the mold and was pressed tightly by the concave and convex molds in the middle. The sheet elements in the trunk trim panel were taken as the research object. The pressures at all point in all directions were equal $\left(P_{r}=P_{z}=P_{O}\right)$, as shown in Figure 4.

The thermoplastic power-law equations are

$$
\begin{aligned}
& \tau_{i j}=\eta_{\alpha} \cdot \dot{\gamma}_{i j}, \\
& \eta_{\alpha}=m \cdot\left|\dot{\gamma}_{i j}\right|^{n-1} .
\end{aligned}
$$

In the equations, $\eta_{\alpha}$ is apparent viscosity, $\eta a ; \gamma_{i j}$ is shear speed, $\mathrm{rad} / \mathrm{s} ; n$ is power-law index; and $m$ is consistency.

The normal stress of the $Z$-axis is

$$
\begin{aligned}
& \tau_{x}=\eta_{\alpha} \cdot \frac{\mathrm{d} u}{\mathrm{~d} z}, \\
& \eta_{\alpha}=m \cdot\left|\frac{\mathrm{d} u}{\mathrm{~d} z}\right|^{n-1} .
\end{aligned}
$$




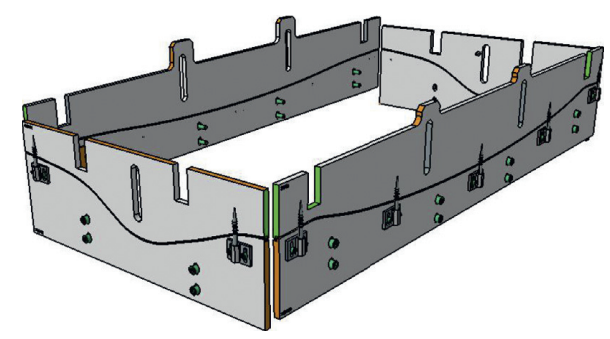

FIgURE 1: Material frame of trunk trim panel.

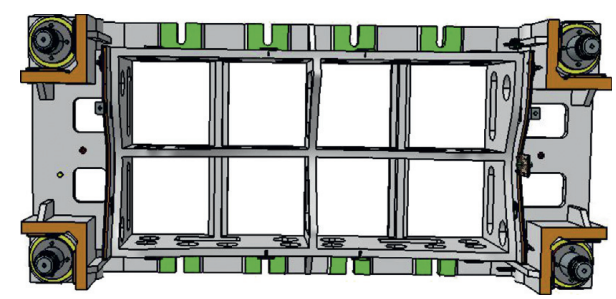

FIGURE 2: Guide postarrangement of trunk trim panel.

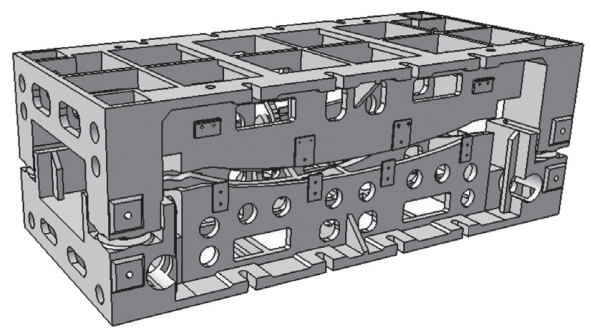

Figure 3: Trunk trim panel mold formwork.

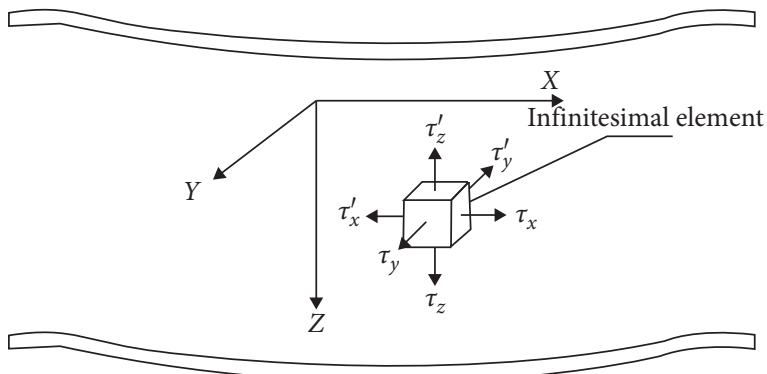

FIgURE 4: Corresponding force.

In the equations, $u$ is $Z$-axis displacement, $\mathrm{m} ; \mathrm{d} u / \mathrm{d} z$ is the shear rate in the $Z$-axis direction, $\mathrm{m} / \mathrm{s}$, which can be obtained from the following equation:

$$
\frac{\mathrm{d} u}{\mathrm{~d} z}=k \cdot \frac{\mathrm{d} P_{z}}{\mathrm{~d} z}
$$

In the previous equation, $\mathrm{d} P_{z} / \mathrm{d} z$ is pressure gradient in the $Z$-axis direction; $k$ is ratio of shear rate to pressure gradient.

According to $\tau_{z}=P_{z}$, substituting equation (5) into equation (4), we get the following two equations:

$$
\begin{aligned}
& P_{z}=\eta_{a} \cdot k \cdot \frac{\mathrm{d} P_{z}}{\mathrm{~d} z}, \\
& P_{z}=m\left|k \cdot \frac{\mathrm{d} P_{z}}{\mathrm{~d} z}\right|^{n-1} \cdot k \cdot \frac{\mathrm{d} P_{z}}{\mathrm{~d} z} .
\end{aligned}
$$

Ignore the positive and negative:

$$
\frac{P_{z}^{(1 / n)}}{m^{(1 / n)} \cdot k} \mathrm{~d} z=\mathrm{d} P_{z}
$$

Integrate on both sides of equation (8):

$$
\begin{aligned}
\int_{0}^{Z} \frac{1}{m^{(1 / n)} \cdot k} \mathrm{~d} z & =\int_{P_{O}}^{P_{z}} P_{z}^{-(1 / n)} \mathrm{d} P_{z} \\
P_{z} & =P_{0}+\left(\frac{Z}{m^{(1 / n)} \cdot k} \cdot \frac{n-1}{n}\right)^{(n /(n-1))} .
\end{aligned}
$$

According to equations (8) and (10), equation (11) is obtained:

$$
a=-\frac{X \ln \left[1+\left(1 / P_{0}\right)\left(\left(Z / m^{(1 / n)} \cdot k\right) \cdot(n-1 / n)\right)^{(n /(n-1))}\right]}{4 Z \eta} .
$$

According to equation (1), equation (12) is obtained:

$$
\begin{aligned}
& \tau_{z}=\eta_{\alpha} \cdot \frac{\mathrm{d} u}{\mathrm{~d} z}=m \cdot\left(\frac{\mathrm{d} u}{\mathrm{~d} z}\right)^{n}, \\
& \tau_{x}=\eta_{\alpha} \cdot \frac{\mathrm{d} v}{\mathrm{~d} x}=m \cdot\left(\frac{\mathrm{d} v}{\mathrm{~d} x}\right)^{n}, \\
& \tau_{y}=\eta_{\alpha} \cdot \frac{\mathrm{d} w}{\mathrm{~d} y}=m \cdot\left(\frac{\mathrm{d} w}{\mathrm{~d} y}\right)^{n} .
\end{aligned}
$$

The ratio of $\tau_{x}$ to $\tau_{z}$ is

$$
\frac{\tau_{x}}{\tau_{z}}=\frac{(\mathrm{d} u / \mathrm{d} z)^{n}}{(\mathrm{~d} v / \mathrm{d} x)^{n}}=\left(\frac{X}{Z}\right)^{n}=\frac{P_{X}}{P_{Z}} .
$$

The calculated equation of the compression molding pressure of the trunk trim panel is

$$
P_{Z}=\left(\frac{X}{Z}\right)^{n} \cdot P_{X}
$$

Equation (14) is the theoretical calculation equation of the compression molding pressure. The length of the trunk trim panel was $X=1305 \mathrm{~mm}$ and the width was $Y=239 \mathrm{~mm}$; take $n=1$ and $P_{X}=2 \mathrm{kPa}$; then the compression molding pressure of the trunk trim panel was $11 \mathrm{MPa}$.

\subsection{Research Studies on Molding Cooling System of Trunk Trim Panel}

2.3.1. Heat Transfer Design of Molding Cooling System of Trunk Trim Panel. The material of the trunk trim panel mold was metal. The water cooling method was used, and the warm water was circulated in a preset channel in the mold to achieve cooling cycle. The cooling system was inserted in the middle of the reinforcing ribs and fixed on the surface of the concave-convex mold by rivets, which was close to the product surface and could conduct heat well for cooling, as shown in Figure 5. 


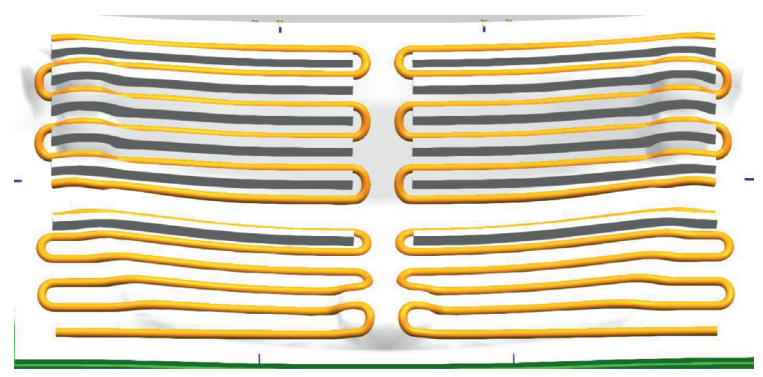

FIgURE 5: Distribution of formwork cooling water pipes.

2.3.2. Heat Transfer Calculation of Molding Cooling System of Trunk Trim Panel. The heat of the trunk trim panel was mainly taken away by the cooling water pipes in the concaveconvex mold. First, the heat that emitted from the trunk trim panel was calculated, and then each parameter of the cooling water pipes was calculated in turn:

$$
\begin{aligned}
\rho & =\rho_{1} V_{1}+\rho_{2} V_{2}, \\
C_{p} & =\frac{\left[C_{1} \cdot V_{1} \cdot \rho_{1}+C_{2} \cdot V_{2} \cdot \rho_{2}\right]}{\rho} .
\end{aligned}
$$

In the equations, $\rho, \rho_{1}$, and $\rho_{2}$ are density of trunk trim panel, PET, PP, and $\mathrm{kg} / \mathrm{m}^{3} ; V_{1}$ and $V_{2}$ are volume of PET、 $\mathrm{PP}$ and $\mathrm{m}^{3}$; and $C_{p}, C_{1}$, and $C_{2}$ are specific heat capacity of trunk trim panel, $\mathrm{PET}, \mathrm{PP}$, and $\mathrm{kJ} / \mathrm{kg}^{\circ} \mathrm{C}$.

The trunk trim panel was $1244 \mathrm{~mm}$ long, $586 \mathrm{~mm}$ wide, and $3 \mathrm{~mm}$ thick. PET had a density of $1.39 \mathrm{~kg} / \mathrm{m}^{3}$, a thickness of $0.8 \mathrm{~mm}$, and a specific heat capacity of 1.1 to $1.4 \mathrm{~kJ} / \mathrm{kg}^{\circ} \mathrm{C}$. The PP had a density of $0.9 \mathrm{~kg} / \mathrm{m}^{3}$, a thickness of $1.45 \mathrm{~mm}$, and a specific heat capacity of $1.926 \mathrm{~kJ} / \mathrm{kg}^{\circ} \mathrm{C}$. Substituting the parameters into equations (15) and (16), the density of the trunk trim panel was $\rho=1.157 \mathrm{~kg} / \mathrm{m}^{3}$ and the specific heat capacity of the trunk trim panel was $C_{p}=1.405 \mathrm{~kJ} / \mathrm{kg}$.

When the trunk trim panel sheet was taken out of the oven after heating, its temperature reached $200^{\circ} \mathrm{C}$, so the sheet must be immediately put into the mold. The material of the trunk trim panel mold was metal, and the water cooling method was used to achieve circulating cooling mold. The heat released by the trunk trim panel is obtained by

$$
Q=m C_{p}\left(T_{1}-T_{2}\right) .
$$

In the previous equation, $m$ is mass of the trunk trim panel, kg; T1 is initial temperature of the trunk trim panel, ${ }^{\circ} \mathrm{C}$; $\mathrm{T} 2$ is demolding temperature of the trunk trim panel, ${ }^{\circ} \mathrm{C}$.

Most of the heat from the trunk trim panel was absorbed through the mold cooling water pipes. The structures of the concave and convex molds of the trunk trim panel were similar, as were the cooling systems, so when the heat absorbed through water pipes is $Q_{2}=Q_{1}$, the heat absorbed through the concave and convex molds is obtained by

$$
Q_{a}=Q_{t}=0.5 Q_{2} .
$$

In the previous equation, $Q_{t}$ is heat absorbed through the convex molding cooling system, J; $Q_{a}$ is heat absorbed through the concave molding cooling system, J.
According to the thermal equilibrium,

$$
V_{a}=V_{t}=\frac{Q_{t}}{\rho_{1} c_{1}\left(\theta_{1}-\theta_{2}\right)}
$$

In the previous equation, $\theta_{1}$ and $\theta_{2}$ are outlet temperature of water in cooling water pipe, and the temperature difference is generally $3^{\circ} \mathrm{C} \sim 5^{\circ} \mathrm{C} ; \rho_{1}$ is density of water, $\mathrm{kg} / \mathrm{m}^{3}$; $c_{1}$ is specific heat capacity of water, $\mathrm{J} /\left(\mathrm{kg} \times{ }^{\circ} \mathrm{C}\right)$.

The initial temperature of the trunk trim panel was $200^{\circ} \mathrm{C}$, and the demolding temperature of the trunk trim panel was $80^{\circ} \mathrm{C}$. The volume of the concave-convex mold is

$$
\begin{aligned}
V_{a}=V_{t} & =\frac{0.5 Q_{2}}{\rho_{1} c_{1}\left(\theta_{1}-\theta_{2}\right) \cdot t} \\
& =\frac{0.5 \cdot m \cdot C_{p} \cdot\left(T_{0}-T\right)}{\rho_{1} c_{1}\left(\theta_{1}-\theta_{2}\right) \cdot t}=9.41 \mathrm{~m}^{3} / \mathrm{min} .
\end{aligned}
$$

According to the relationship between the volume flow of the cooling water pipes and the diameter of the pipes, the diameter of the cooling water pipes was determined to be $d=16 \mathrm{~mm}$.

The minimum distance between two water holes should not be less than $1.7 \mathrm{~d}$ (hole diameter), and the maximum should be $3 \mathrm{~d}$. The size of the hole depended on the size of its molded product, which was the size of its mold or mold cavity. Due to the large trunk trim panel parts, the maximum distance between cold water holes was $3 \mathrm{~d}$, which was $48 \mathrm{~mm}$, and the roundness was $50 \mathrm{~mm}$.

\section{Orthogonal Experiments on the Molding of Trunk Trim Panel}

In this paper, there were four level factors. Taguchi test design is a method of selecting test conditions and arranging tests using an orthogonal table and is a further method based on the orthogonal test method; but this article only conducts orthogonal tests [8]. Under the condition that multiple important factors changed at the same time, the most effective design method was orthogonal experiments. This chapter will discuss the molding process parameters of the trunk trim panel, determine the level factors and evaluation indicators, design and complete the orthogonal experiments of molding, and perform range analyses on the measurement results to obtain the degree of the influence of the process parameters on product quality and the best process parameters corresponding to each of the evaluation indicators.

\subsection{Conditions of Orthogonal Experiments on Molding of Trunk Trim Panel}

3.1.1. Experimental Equipment. PET + PP composite material was used for the orthogonal test of the trunk decorative plate molding. 
Effective size of the oven of the trunk trim panel is as follows: depth $1900 *$ width $2530 *$ height $500 \mathrm{~mm}$. Temperature range is $10^{\circ} \mathrm{C} \sim 300^{\circ} \mathrm{C}$. Equipment heating power is $36 \mathrm{~kW}$. The thickness of cold-rolled plate outside the box is $1.2 \mathrm{~mm}$. The material of the liner is $1.2 \mathrm{~mm} 304$ stainless steel. The trunk trim panel had good fire resistance and sound insulation.

The material of the mold of the trunk trim panel was 45 \# cast steel, whose weight was two tons and service life was up to 300,000 sets. The cooling method was water cooling. The distance between the water pipes was $80 \mathrm{~mm}$. The mold temperature was less than $8-10^{\circ} \mathrm{C}$. The mold was transported by forklift fork. The fixing method was to fix with platen grooves. The width of the platen grooves was $30 \mathrm{~mm}$, and the interval of the platen grooves was $300 \mathrm{~mm}$. The platen grooves were evenly arranged.

The press for the trunk trim panel used YMG32-315 four-column hydraulic press.

3.1.2. Experimental Process. First, the raw materials were put into the oven and the corresponding temperature and heating time were set. After the heating was completed, the materials were taken out into the mold and fixed with a material pin to maintain the pressure. After reaching the set time, the material was taken out, and the excess scrap was removed and set aside for cooling. This operation was repeated to complete 16 orthogonal experiments. The specific experiment steps are shown in Figures 6 to 15.

3.2. Level Factors of the Molding of Trunk Trim Panel. The steps of the molding of the trunk prim panel were as follows: heating the molding to a certain temperature in the oven, taking it out, placing it in the concave-convex mold for compression molding, taking it out after maintaining the pressure and cooling, and removing the excess scrap. The main level factors that affected compression molding were heating temperature, heating time, compression pressure, and holding time.

3.2.1. Heating Temperature. Since thermosetting plastics needed to be cured within a certain temperature range, proper heating temperature was important. The molding temperature of PET in the trunk trim panel was $270-290^{\circ} \mathrm{C}$, and the molding temperature of PP was $190-210^{\circ} \mathrm{C}$. PET covered the surface of the sheet; it had a small thickness and was reticulate. Therefore, the molding of the trunk trim panel mainly depended on the deformation of the PP material, the heating temperature, and the temperature of the molding of PP. It was sure that the sheet did not scorch or stick to the oven.

3.2.2. Heating Time. Proper heating time could improve the yield rate of the finished products, so proper heating time was important. Su et al. [9] show that the heating time was the time for heating the sheet to be able to be molded. Zhu et al. [10] show that the heating time of the trunk trim panel

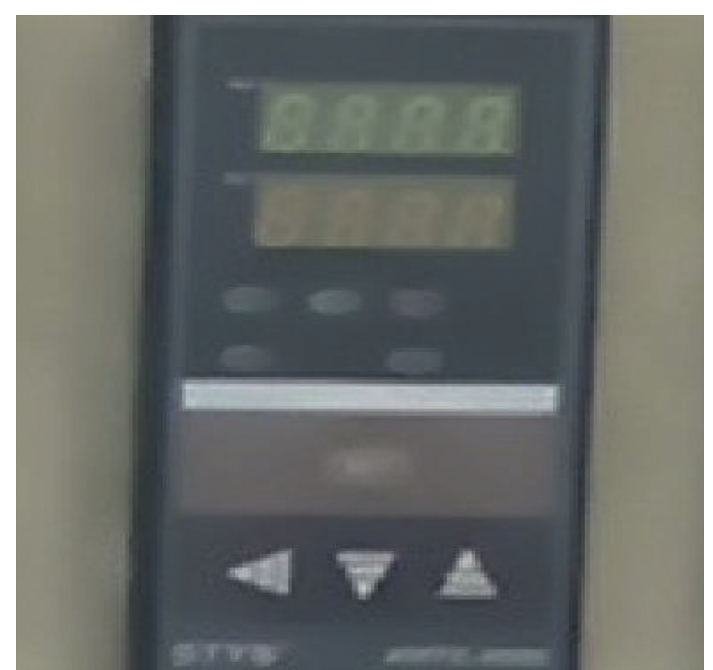

FIgURE 6: Setting heating temperature.

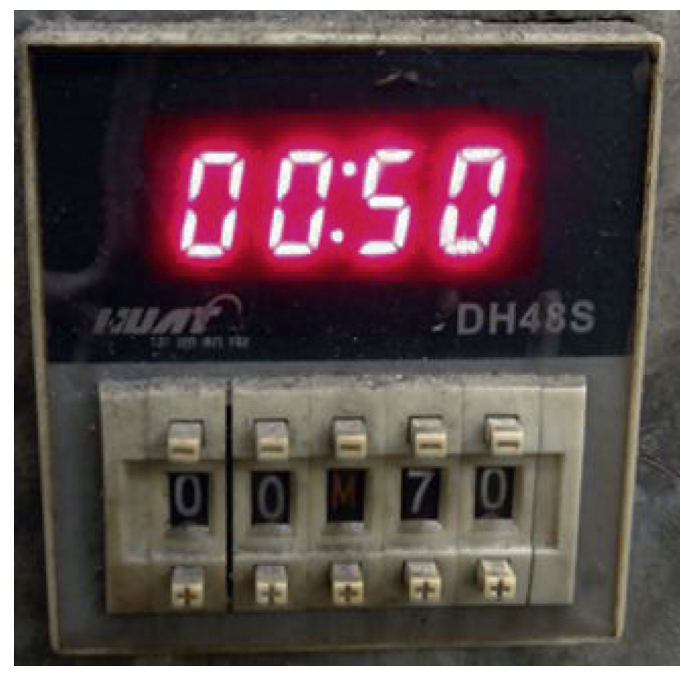

Figure 7: Setting heating time.

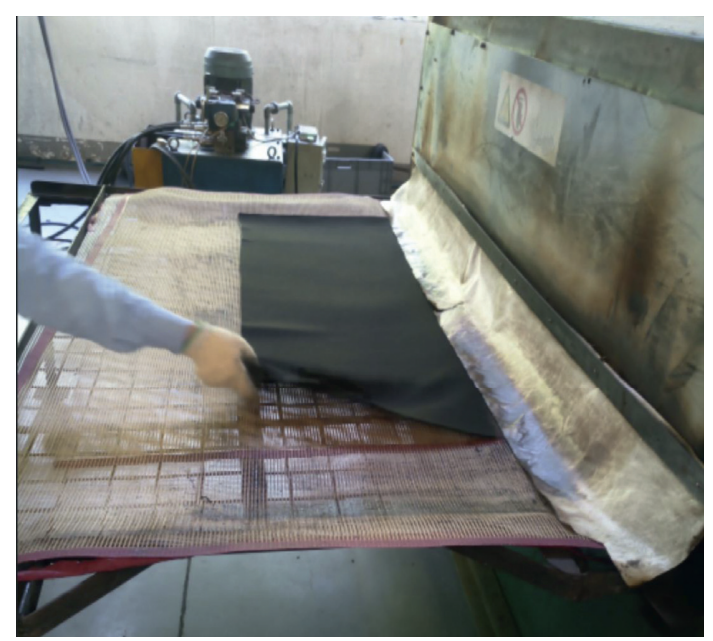

Figure 8: Heating raw material. 


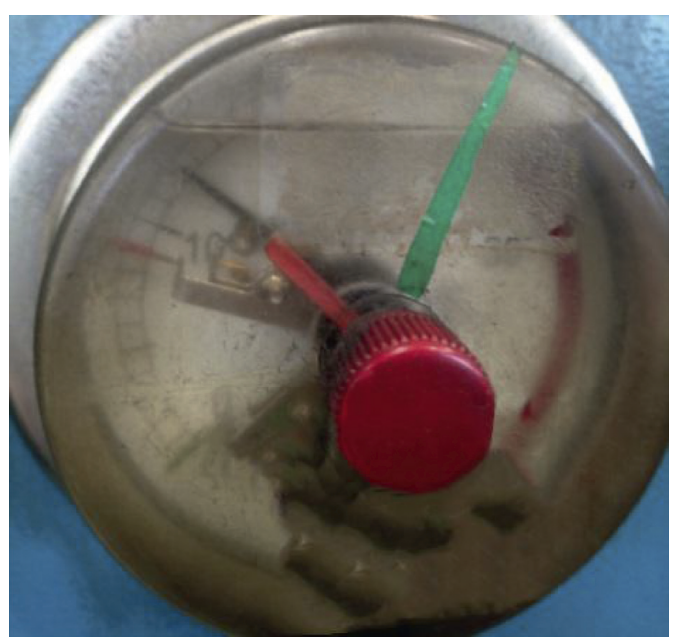

FIGURE 9: Setting molding pressure.

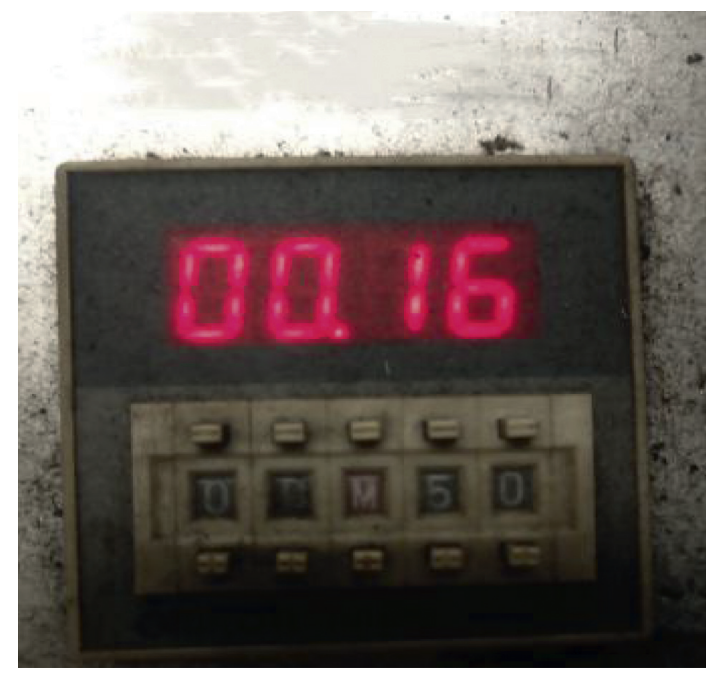

Figure 10: Setting dwell time.

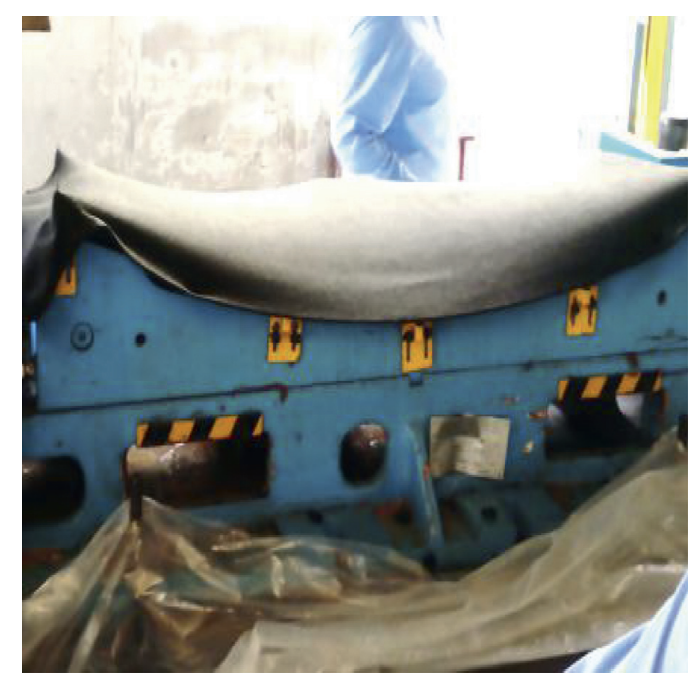

FIGURE 11: Fixing sheet.

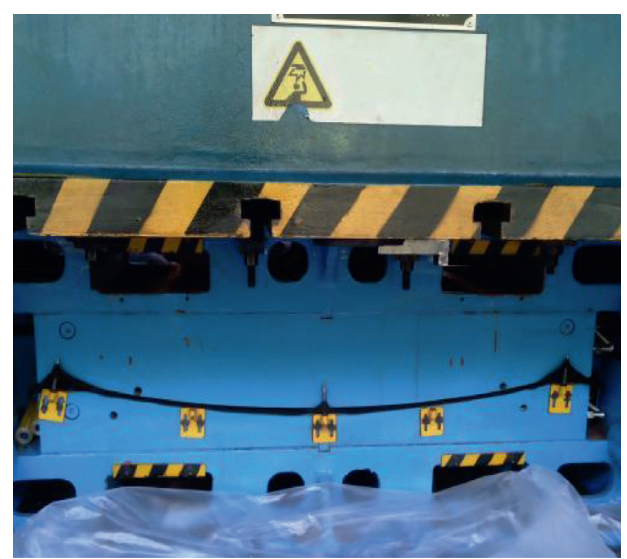

FIgURE 12: Raw material molding.

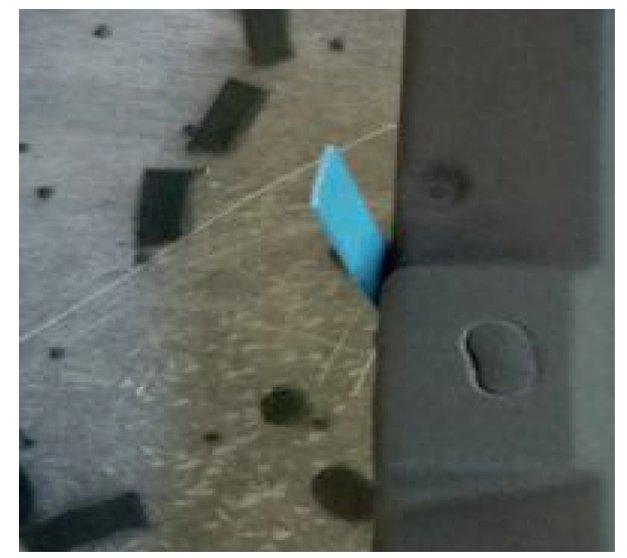

FIgURE 13: Removing scrap.

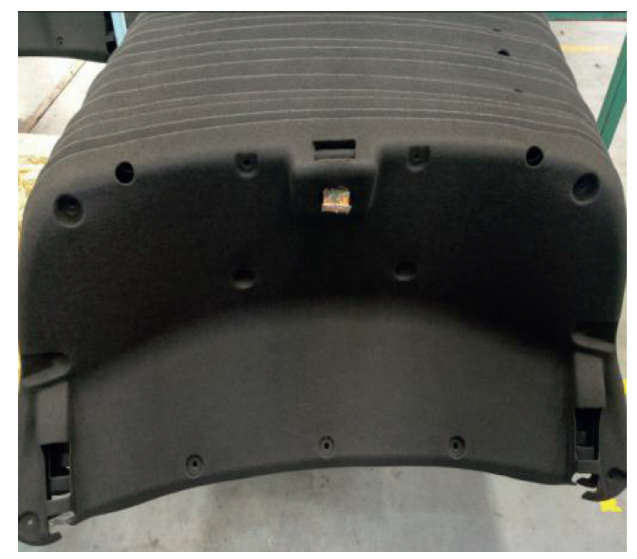

Figure 14: Cooling. 


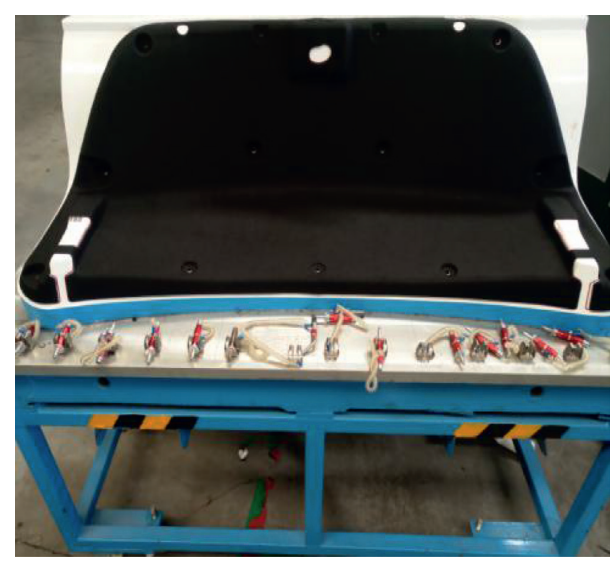

FIgURE 15: Check.

referred to the calculation formula of hot air preheating time:

$$
t=70.9521+0.2318 d-0.2810 T \text {. }
$$

In the previous formula, $t$ is suitable preheating time, min; $d$ is sheet thickness, $\mathrm{mm}$; and $T$ is hot air temperature, ${ }^{\circ} \mathrm{C}$.

The thickness of the trunk trim panel was $3 \mathrm{~mm}$, and the temperature of the hot air was $250^{\circ} \mathrm{C}$; then $t$ was $1.3975 \mathrm{~min}$.

3.2.3. Molding Pressure. In addition to the effects of molding temperature and dwell time, the molding accuracy of trunk trim panel also mainly depended on the molding pressure of the mold. Appropriate molding pressure not only improved the product quality but also made up for the shortage if other industrial parameters were not adequate [11]. According to equation (14), the molding pressure of the trunk trim panel was $11 \mathrm{MPa}$.

3.2.4. Holding Time. The holding time was the length of time from start molding to the opening mold. It was an important factor to ensure the heat dissipation and shaping. The heat of the trunk trim panel was mainly consumed by the cooling water pipes. The dwell time was calculated by the heat transferred by the trunk trim panel. According to the Fourier differential equation in the case of one-dimensional heat conduction, the dwell time was $60 \mathrm{~s}$.

The production of trunk trim panel in the workshop was observed and the process parameters of the production process were calculated. After consulting the relevant information and combining the actual situation, the four factors were taken up and down, respectively, as shown in Table 1.

3.3. Evaluation Indicators of Orthogonal Experiments on Molding of Trunk Trim Panel. The main defects of trunk prim panel were cracking, wrinkling, and shrinking. Taking these three defects as indicators was more abstract and the measurement was more complicated, so the maximum thinning rate, maximum thickening rate, and shrinkage rate were used to replace these three indicators.

3.3.1. Maximum Thinning Rate of Trunk Trim Panel. The thinning rate was one of the important indicators for evaluating the results of orthogonal experiments. The trunk trim panel was not a regular part, and its sheet was subjected to uneven forces during the molding process. Therefore, for the measurement of the maximum thinning rate, the points at different positions were used for measurement. The thickness of the round hole and its surroundings could be ignored. Five points were measured as shown in Figure 16, a maximum value was removed, and the second maximum thinning rate was taken:

$$
B=\frac{x-3}{3} \times 100 \%
$$

3.3.2. Maximum Thickening Rate of Trunk Trim Panel. The thickening rate was one of the important indicators for evaluating the results of orthogonal experiments. The measurement of the maximum thickening of the trunk trim panel was similar to that of the maximum thinning rate. Five points were measured as shown in Figure 16, a maximum value was removed, and the second maximum thickening rate was taken:

$$
H=\frac{y-3}{3} \times 100 \%
$$

3.3.3. Shrinkage Rate of Trunk Trim Panel. The shrinkage rate was one of the important indicators for evaluating the results of orthogonal experiments. The mold of the trunk trim panel and four assembly holes were selected. The mutual distance between points was measured and the shrinkage of each segment was calculated, as shown in Figure 17. The average value was used as the shrinkage rate of the trunk trim panel. The formula is

$$
\eta=\frac{1}{4}\left(\frac{A-a}{A}+\frac{B-b}{B}+\frac{C-c}{C}+\frac{D-d}{D}\right) .
$$

3.3.4. Comprehensive Weighted Scoring Method. There were three evaluation indicators in the orthogonal experiments; in order to obtain the trunk trim panel with the best comprehensive evaluation indicators, a comprehensive weighted scoring method was used. The comprehensive indicator $y$ can be expressed as follows:

$$
y=a_{1} y_{1}+a_{2} y_{2}+a_{3} y_{3} .
$$

In the previous formula, $a_{1}, a_{2}$, and $a_{3}$ are the importance of each evaluation indicator; $y_{1}, y_{2}$, and $y_{3}$ are score of each evaluation indicator.

The sum of $a_{1}, a_{2}$, and $a_{3}$ was set to 1 . The three evaluation indicators of maximum thinning rate, maximum thickening rate, and shrinkage rate had similar effects on the product quality, but the shrinkage rate was directly related to 
TABLE 1: Level factors of orthogonal experiments.

\begin{tabular}{lcccc}
\hline Level & Heating temperature $\left({ }^{\circ} \mathrm{C}\right)$ & Heating time $(\mathrm{s})$ & Molding pressure $(\mathrm{kPa})$ & Holding time $(\mathrm{s})$ \\
\hline 1 & 190 & 50 & 11 & 40 \\
2 & 200 & 60 & 13 & 50 \\
3 & 210 & 70 & 15 & 60 \\
4 & 220 & 80 & 17 & 70 \\
\hline
\end{tabular}

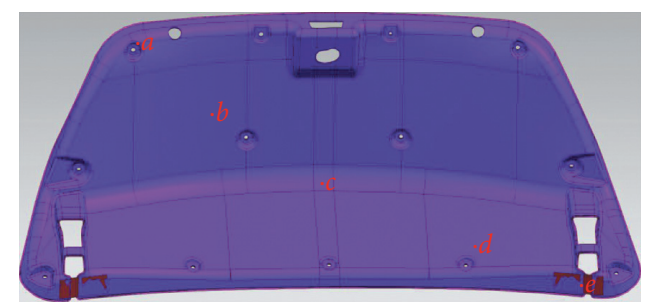

FIgURE 16: Measurement points for maximum thinning rate and thickening rate.

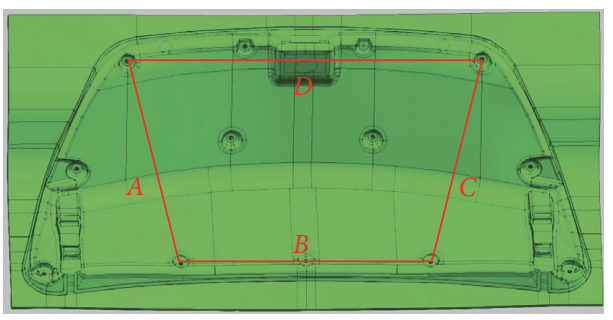

(a)

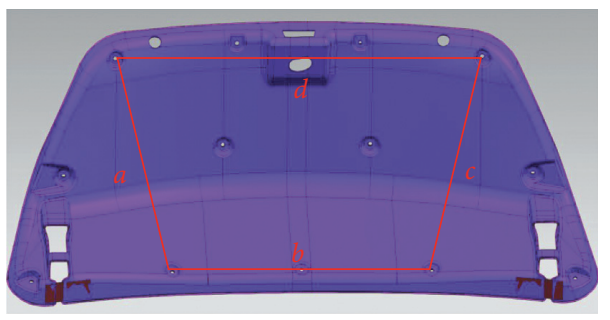

(b)

FIGURE 17: Trunk trim panel and shrinkage measuring segments.

the trunk trim panel and was directly related to whether the trunk trim panel could be installed on the sheet metal, so $a_{1}=0.3, a_{2}=0.3, a_{3}=0.4$ were set. For the determination of the scores, the trunk trim panel could be sorted according to the evaluation indicators, with the best being 100 , followed by 98 , and decreasing in order.

3.4. Design and Results of Orthogonal Experiments. The experiments, maximum thinning rate, maximum thickening rate, and shrinkage rate of the trunk trim panel were measured. The results are shown in Table 2.

3.5. Analyses of the Results of Orthogonal Experiments. In order to obtain the degree of influence of each evaluation indicator and the optimal process parameter combination of the evaluation indicators, a range analysis was performed on the orthogonal experiments results of the trunk trim panel [12], as shown in Tables 3-5.

3.5.1. The Influence of Various Factors on the Maximum Thinning Rate. From Table 3, it can be concluded that the influence of each factor on the maximum thinning rate should be as follows: holding time $>$ heating temperature $>$ molding pressure $>$ heating time. The holding time had the greatest effect. The best solution was $A_{4} B_{3} C_{4} D_{2}$. When the heating temperature was $220^{\circ} \mathrm{C}$, the heating time was $70 \mathrm{~s}$, the mold pressure was $17 \mathrm{kPa}$, and the holding pressure time was $50 \mathrm{~s}$, the thinning rate was the smallest.

3.5.2. The Influence of Various Factors on the Maximum Thickening Rate. From Table 4, it can be concluded that the influence of each factor on the maximum thickening rate should be as follows: holding time $>$ heating temperature $>$ molding pressure $>$ heating time. Holding time had the greatest effect. The best solution was $A_{4} B_{3} C_{4} D_{2}$. When the heating temperature was $190^{\circ} \mathrm{C}$, the heating time was $80 \mathrm{~s}$, the molding pressure was $15 \mathrm{kPa}$, and the holding pressure time was $50 \mathrm{~s}$, the maximum thickening rate was the smallest.

3.5.3. The Influence of Various Factors on the Shrinkage Rate. From Table 5, it can be concluded that the influence of each factor on the shrinkage rate should be as follows: heating temperature $>$ molding pressure $>$ heating time $>$ holding time. The heating temperature had the greatest effect. The best solution was $A_{2} B_{3} C_{3} D_{2}$. When he heating temperature was $200^{\circ} \mathrm{C}$, the heating time was $70 \mathrm{~s}$, the mold pressure was $15 \mathrm{kPa}$, and the dwell time was $50 \mathrm{~s}$, the shrinkage rate was the smallest.

3.5.4. Data Processing of Comprehensive Weighted Scoring Method. The comprehensive scoring method was used to analyze the results of the compression molding experiments 
TABLE 2: Results of orthogonal experiments.

\begin{tabular}{|c|c|c|c|c|c|c|c|}
\hline $\begin{array}{l}\text { Serial } \\
\text { number }\end{array}$ & $\begin{array}{c}\text { Heating } \\
\text { temperature }\left({ }^{\circ} \mathrm{C}\right)\end{array}$ & $\begin{array}{l}\text { Heating } \\
\text { time }(\mathrm{s})\end{array}$ & $\begin{array}{c}\text { Pressure } \\
(\mathrm{kPa})\end{array}$ & $\begin{array}{l}\text { Compress } \\
\text { time }(s)\end{array}$ & $\begin{array}{l}\text { Maximum thinning } \\
\text { rate }(\%)\end{array}$ & $\begin{array}{c}\text { Maximum } \\
\text { thickening rate (\%) }\end{array}$ & $\begin{array}{c}\text { Shrinkage } \\
(\%)\end{array}$ \\
\hline 1 & 190 & 50 & 11 & 40 & 30.78 & 4.82 & 0.96 \\
\hline 2 & 190 & 60 & 13 & 50 & 28.47 & 4.43 & 1.02 \\
\hline 3 & 190 & 70 & 15 & 60 & 29.86 & 4.4 & 0.83 \\
\hline 4 & 190 & 80 & 17 & 70 & 30.44 & 4.32 & 0.88 \\
\hline 5 & 200 & 50 & 13 & 60 & 30.89 & 4.77 & 0.86 \\
\hline 6 & 200 & 60 & 11 & 70 & 30.43 & 4.85 & 1.04 \\
\hline 7 & 200 & 70 & 17 & 40 & 28.83 & 4.96 & 0.86 \\
\hline 8 & 200 & 80 & 15 & 50 & 28.79 & 4.51 & 0.82 \\
\hline 9 & 210 & 50 & 15 & 70 & 30.33 & 4.6 & 1.07 \\
\hline 10 & 210 & 60 & 17 & 60 & 29.97 & 4.74 & 1.11 \\
\hline 11 & 210 & 70 & 11 & 50 & 29.51 & 4.61 & 0.83 \\
\hline 12 & 210 & 80 & 13 & 40 & 29.05 & 4.43 & 1.09 \\
\hline 13 & 220 & 50 & 17 & 50 & 28.08 & 4.41 & 1 \\
\hline 14 & 220 & 60 & 15 & 40 & 28.7 & 4.88 & 0.82 \\
\hline 15 & 220 & 70 & 13 & 70 & 29.12 & 4.45 & 1.02 \\
\hline 16 & 220 & 80 & 11 & 60 & 29.9 & 4.71 & 1.13 \\
\hline
\end{tabular}

TABLE 3: Influence of various factors on the maximum thinning rate.

\begin{tabular}{lcccc}
\hline & Heating temperature $\left({ }^{\circ} \mathrm{C}\right)$ & Heating time $(\mathrm{s})$ & Pressure $(\mathrm{kPa})$ & Compress time $(\mathrm{s})$ \\
\hline$K 1$ & 119.55 & 120.08 & 120.64 & 117.36 \\
$K 2$ & 118.94 & 117.58 & 117.52 & 117.68 \\
$K 3$ & 118.86 & 117.32 & 117.32 & 120.64 \\
$K 4$ & 115.8 & 118.18 & 30.16 & 123.2 \\
$k 1$ & 29.89 & 30.02 & 29.38 & 29.34 \\
$k 2$ & 29.73 & 29.39 & 29.42 & 28.71 \\
$k 3$ & 29.72 & 29.33 & 29.33 & 30.16 \\
$k 4$ & 28.95 & 29.55 & 0.83 & 30.08 \\
Range & 0.94 & 0.69 & 4 & 1.44 \\
Combination & 4 & 3 & 2 \\
\hline
\end{tabular}

TABLE 4: Influence of various factors on the maximum thickening rate.

\begin{tabular}{lcccc}
\hline & Heating temperature $\left({ }^{\circ} \mathrm{C}\right)$ & Heating time $(\mathrm{s})$ & Pressure $(\mathrm{kPa})$ & Compress time $(\mathrm{s})$ \\
\hline K1 & 17.97 & 18.60 & 19 & 18.08 \\
$K 2$ & 19.08 & 18.90 & 18.4 & 17.96 \\
$K 3$ & 18.38 & 18.42 & 18.44 & 18.64 \\
$K 4$ & 18.45 & 17.97 & 4.75 & 18.24 \\
$k 1$ & 4.49 & 4.65 & 4.52 & 4.77 \\
$k 2$ & 4.77 & 4.73 & 4.60 & 4.49 \\
$k 3$ & 4.59 & 4.60 & 4.61 & 4.66 \\
$k 4$ & 4.61 & 4.49 & 0.23 & 0.282 \\
Range & 0.280 & 0.2 & 2 & 2 \\
Combination & 1 & 4 & & 2 \\
\hline
\end{tabular}

of the trunk trim panel. The data of the 16 groups of experiment results were superimposed, and the scores are shown in Table 6 below.

According to the comprehensive scoring method, it can be obtained that the eighth group had the highest score, 93.8 points, which was the best process parameter combination, and the corresponding scheme was $A_{1} B_{4} C_{2} D_{2}$. When the heating temperature was $200^{\circ} \mathrm{C}$, the heating time was $70 \mathrm{~s}$, the holding pressure was $11 \mathrm{kPa}$, and the holding pressure time was $40 \mathrm{~s}$, the trunk trim panel could have a good comprehensive quality of three evaluation indicators.

\section{Optimization of Molding Parameters of Trunk Trim Panel Based on Neural Network and Genetic Algorithm}

A neural network model for optimizing the molding parameters of the trunk trim panel was established. The model described the relationship between the processing parameters and the maximum thinning rate, maximum thickening rate, and shrinkage rate. The prediction function of neural network was used to predict the maximum thinning rate, maximum thickening rate, and shrinkage 
TABLE 5: Influence of various factors on shrinkage.

\begin{tabular}{lcccc}
\hline & Heating temperature $\left({ }^{\circ} \mathrm{C}\right)$ & Heating time $(\mathrm{s})$ & Pressure $(\mathrm{kPa})$ & Compress time $(\mathrm{s})$ \\
\hline$K 1$ & 3.68 & 3.89 & 3.96 & 3 \\
K2 & 3.58 & 3.98 & 3.56 & 3.68 \\
$K 3$ & 4.09 & 3.54 & 3.84 & 3.92 \\
$K 4$ & 3.98 & 3.91 & 0.99 & 4 \\
$k 1$ & 0.92 & 0.97 & 1 & 0.93 \\
$k 2$ & 0.9 & 1.00 & 0.89 & 0.92 \\
$k 3$ & 1.03 & 0.89 & 0.96 & 0.98 \\
$k 4$ & 0.99 & 0.98 & 0.115 & 1 \\
Range & 0.13 & 0.112 & 3 & 0.09 \\
Combination & 2 & 3 & 2 \\
\hline
\end{tabular}

TABLE 6: Comprehensive scoring results of compression molding of trunk trim panel.

\begin{tabular}{lccccccc}
\hline $\begin{array}{l}\text { Serial } \\
\text { number }\end{array}$ & $\begin{array}{c}\text { Maximum thinning rate } \\
(\%)\end{array}$ & Score & $\begin{array}{c}\text { Maximum thickening rate } \\
(\%)\end{array}$ & Score & $\begin{array}{c}\text { Shrinkage } \\
(\%)\end{array}$ & $\begin{array}{c}\text { Score } \\
\text { Comprehensive weighted score } \\
(\%)\end{array}$ \\
\hline 1 & 30.78 & 72 & 4.82 & 76 & 0.96 & 86 & 78.8 \\
2 & 28.47 & 98 & 4.43 & 92 & 1.02 & 82 & 89.8 \\
3 & 29.86 & 84 & 4.4 & 98 & 0.83 & 94 & 92.2 \\
4 & 30.44 & 74 & 4.32 & 100 & 0.88 & 88 & 87.4 \\
5 & 30.89 & 70 & 4.77 & 78 & 0.86 & 92 & 78 \\
6 & 30.43 & 76 & 4.85 & 74 & 1.04 & 78 & 76.2 \\
7 & 28.83 & 92 & 4.96 & 70 & 0.86 & 90 & 84.6 \\
8 & 28.79 & 94 & 4.51 & 88 & 0.82 & 98 & 76 \\
9 & 30.33 & 78 & 4.6 & 86 & 1.07 & 76 & 79.6 \\
10 & 29.97 & 80 & 4.74 & 80 & 1.11 & 72 & 76.8 \\
11 & 29.51 & 86 & 4.61 & 84 & 0.83 & 96 & 89 \\
12 & 29.05 & 90 & 4.43 & 94 & 1.09 & 74 & 84.8 \\
13 & 28.08 & 100 & 4.41 & 96 & 1 & 84 & 92.4 \\
14 & 28.7 & 96 & 4.88 & 72 & 0.82 & 100 & 80.4 \\
15 & 29.12 & 88 & 4.45 & 90 & 1.02 & 80 & 70 \\
\hline
\end{tabular}

rate of plastic parts, which verified the correctness and reliability of the established neural network model [13]. The genetic algorithm was used to obtain the optimal combination of process parameters for molding of trunk trim panel, which could verify the results of compression molding experiments.

The optimization of process parameters by orthogonal experiments was only a combination of rough values, which were not representative. There was also a good possibility that the value not taken was the optimal parameter. To compensate for this deficiency, BP neural network and genetic algorithm could be used to optimize process parameters [14]. The content of this section is based on the orthogonal test in Table 2. Because part of the data has a large deviation during the training of $\mathrm{BP}$ neural network and genetic algorithm, only $60 \%$ of the data is finally used.

4.1. Neural Network and Genetic Algorithm of Trunk Trim Panel. Lin et al. [15] show that neural network was a model that could simulate the neural structure of the human brain to deal with information. Compared with traditional logic, the advantage is to have simple processing power, as described by Wang et al. [16]. Yin et al. [17] show that the essential meaning of the BP algorithm was that the forward transmission signal and the backward transmission error signal made up the learning phase. In BP algorithm, multilayer feedforward was most commonly used, and single hidden layer was most common, which could approximate most nonlinear functions, as described by Yin et al. [18] In this paper, a three-layer neural network is used to establish a neural network model for optimizing the molding parameters of the trunk decorative board.

\subsection{Design of Neural Network Model of Trunk Trim Panel}

4.2.1. Determine the Number of Neurons in Each Layer. The orthogonal experiment in this paper has 4 process parameters and 3 evaluation indexes. Therefore, the input layer has 4 neurons and the output layer contains 3 neurons.

The number of hidden layer neurons can be determined by

$$
\begin{aligned}
& m=\sqrt{n+t}+a, \\
& m=\log _{2} n, \\
& m=\sqrt{n t} .
\end{aligned}
$$

In the previous formula, $m$ is number of neurons in the hidden layer; $n$ is number of neurons in the input layer; $t$ is number of neurons in the output layer; and $a$ is constant from 1 to 10 . 
According to the formula, by $n=4$ and $t=3, m$ can take a constant from 4 to 12 . Find the network error of the number of nodes in each hidden layer. The results are shown in Table 7. The least error 9 is selected as the final result.

4.2.2. Excitation Function of Each Layer. The hidden layer selected the hyperbolic tangent S-shaped transfer function tansig, and the output layer selected purelin.

4.2.3. Training Function. The training function selected the trainlm function with fast convergence and small error, as shown in Figure 18.

4.2.4. Improved Normalization of Training Methods. The values and units of different process parameters were different. In order to be able to compare and comprehensively evaluate the data, the data are normalized:

$$
x^{\prime}=\frac{x-x_{\min }}{x_{\max }-x_{\min }} .
$$

To speed up the training, equation (27) is modified to

$$
x^{\prime}=0.05+0.095 \frac{x-x_{\min }}{x_{\max }-x_{\min }} .
$$

$x_{\max }$ is the maximum and $x_{\min }$ is the minimum. The corresponding back normalization formula is

$$
x=\frac{\left(x^{\prime}-0.05\right)\left(x_{\max }-x_{\min }\right)}{0.95}+x_{\min } .
$$

4.2.5. Artificial Neural Network Model Optimized by Genetic Algorithm for Trunk Trim Panel. Genetic algorithm could optimize neural network by optimizing weights and optimizing structure and parameters. The first method was relatively simple and conformed to the connotation of neural networks. Therefore, this paper chose the first method. The specific process is shown in Figure 19.

The population was the selected training sample. If the size of the population was large, then the calculation speed was slow. If the size of the population was small, then the calculation error was large. Therefore, the size of the group should be selected between 10 and 200 according to the actual situation. In this paper, the size of the population was selected to 50, the roulette wheel selection was selected, the crossover operation used a basic crossover rate of 0.9 , and a hybrid crossover method with an adaptive crossover rate of 0.5 was introduced.

\subsection{Training and Testing of the Algorithm of the Trunk Trim} Panel. The test numbers of the randomly selected training samples were 2, 3, 4, 6, 6, 7, 9, 10,11,13,14, 15, and 16, and the test numbers of the test samples were $1,5,8$, and 12 .

MATLAB was used to train and test the data and the results are as follows.
TABLE 7: Network errors of different hidden layer nodes.

\begin{tabular}{lcccc}
\hline Number of nodes & 4 & 5 & 6 & 7 \\
\hline Network error & $5.26 E-04$ & $6.37 E-04$ & $9.26 E-04$ & $9.59 E-04$ \\
8 & 9 & 10 & 11 & 12 \\
$2.92 E-04$ & $1.71 E-04$ & $9.95 E-04$ & $4.60 E-04$ & $7.70 E-04$ \\
\hline
\end{tabular}

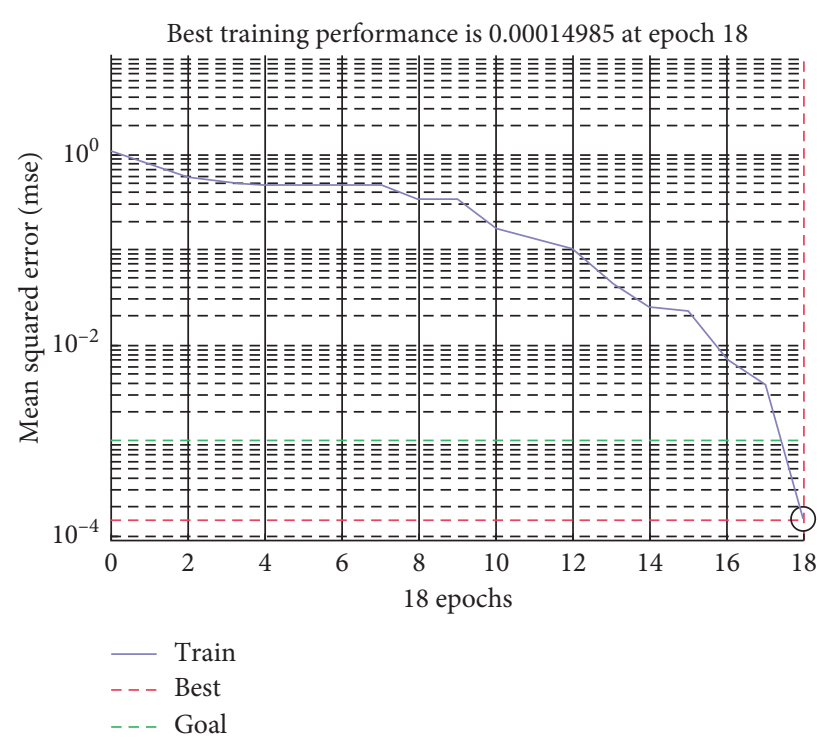

Figure 18: Performance curve of the network (trainbfg training function).

It can be seen from Figure 20 that, after 9 trainings, the network error reached the set accuracy. It can be seen from Figures 21 and 22 that the predicted value of the neural network optimized by the genetic algorithm was almost the same as the real value, but the BP neural network had a little error.

4.4. Impact of the Optimization Results of the Neural Network Optimization of the Trunk Trim Panel on the Evaluation Indicators. In order to study the changing trend of the evaluation indicators of the trunk trim panel as the process parameters changed, the optimal process parameter combination was used as the base. The prediction function of the established neural network was used to predict the maximum thinning rate, maximum thickening rate, and shrinkage rate under a single process parameter; then the influence law of a single process parameter on the maximum thinning rate, maximum thickening rate, and shrinkage rate was obtained.

It can be seen from Figure 23 that the maximum thinning rate became smaller as the heating temperature and molding pressure became larger and became smaller and then larger as the heating time and the holding pressure time became larger.

It can be seen from Figure 24 that the maximum thickening rate became larger and then smaller as the heating temperature and heating time became larger, 


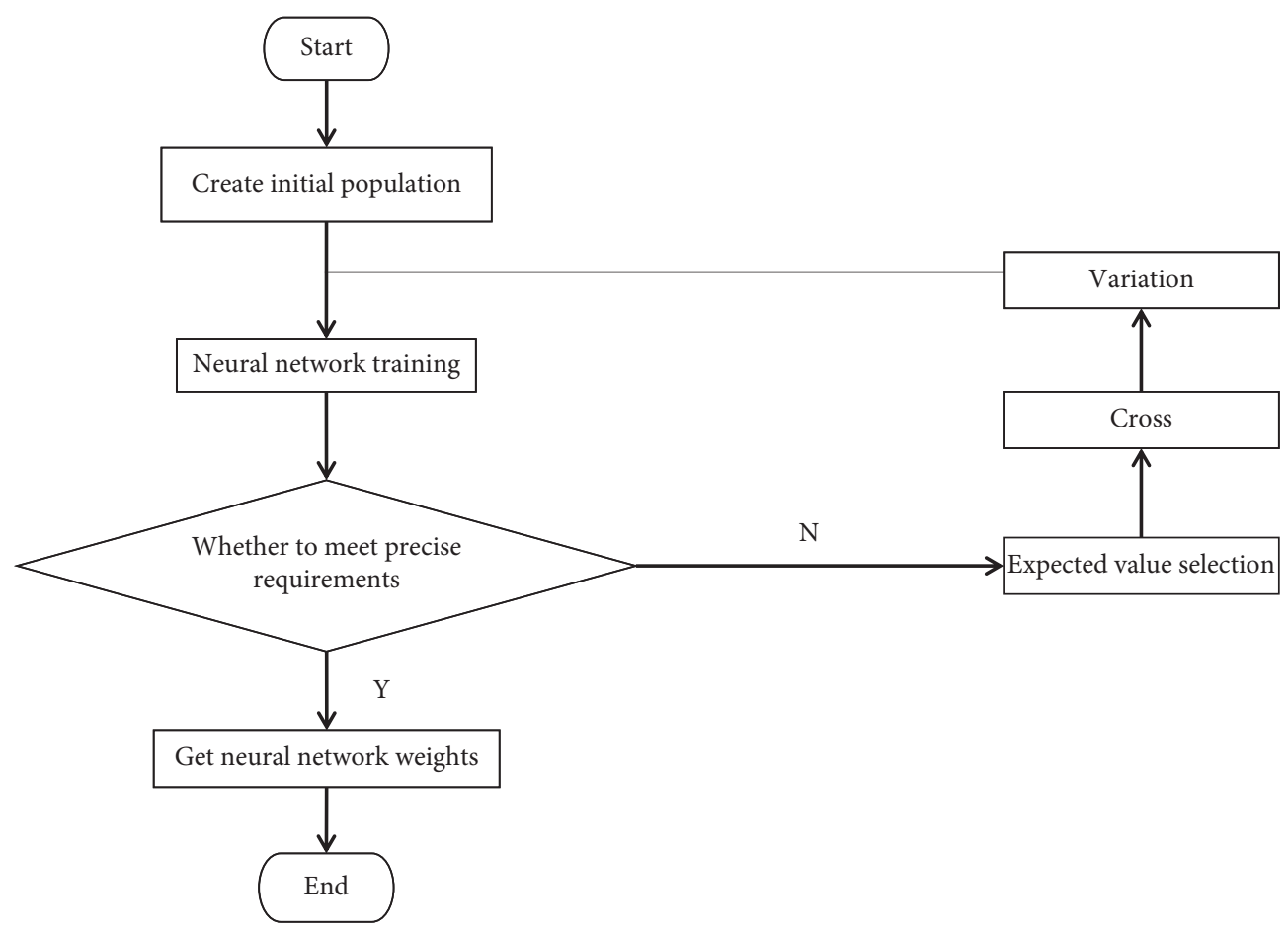

FIGURE 19: Flow chart of genetic algorithm of optimized neural network weights.

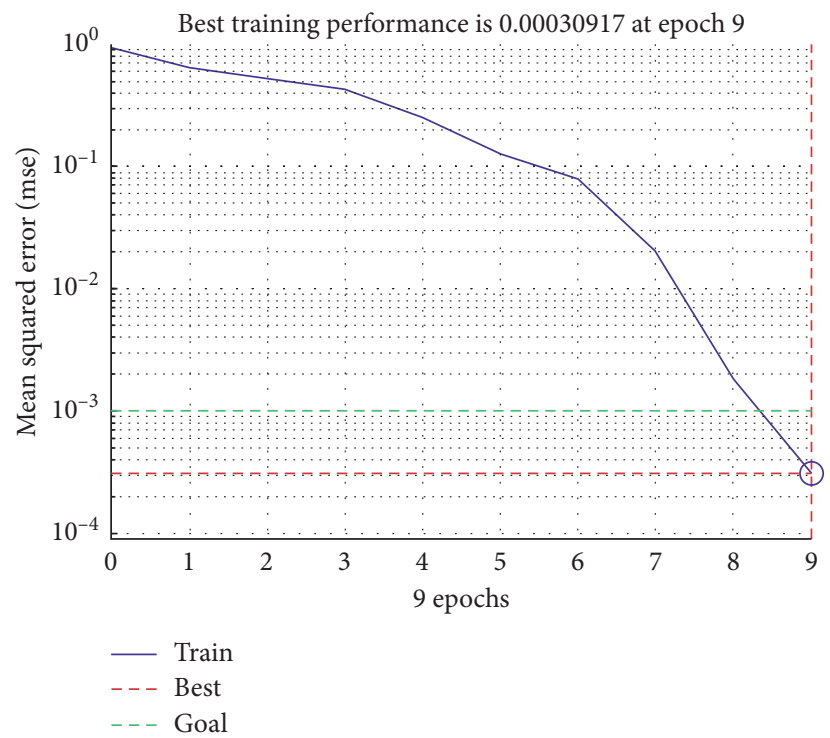

FigURE 20: Network performance curve.

became smaller and then larger as the mold pressure and holding time became larger, and then stabilized.

It can be seen from Figure 25 that the shrinkage rate became larger and then smaller as the heating temperature became larger, became smaller and then larger as the heating time and the mold pressure became larger, and became larger and then smaller with the dwell time.

4.5. Optimization of Process Parameters Based on Genetic Algorithm. The neural network model described the relationship between the process parameters of the trunk trim panel and the maximum thinning rate, maximum thickening rate, and shrinkage rate. The model could accurately predict each evaluation indicator and studied the trend of evaluation indicators changing with process parameters. Due to the mixed influence of process parameters on the evaluation indicators, the model could not solve the best process parameters. Therefore, it is necessary to use intelligent optimization technology to globally optimize process parameters. This section will build an optimization model of process parameters based 


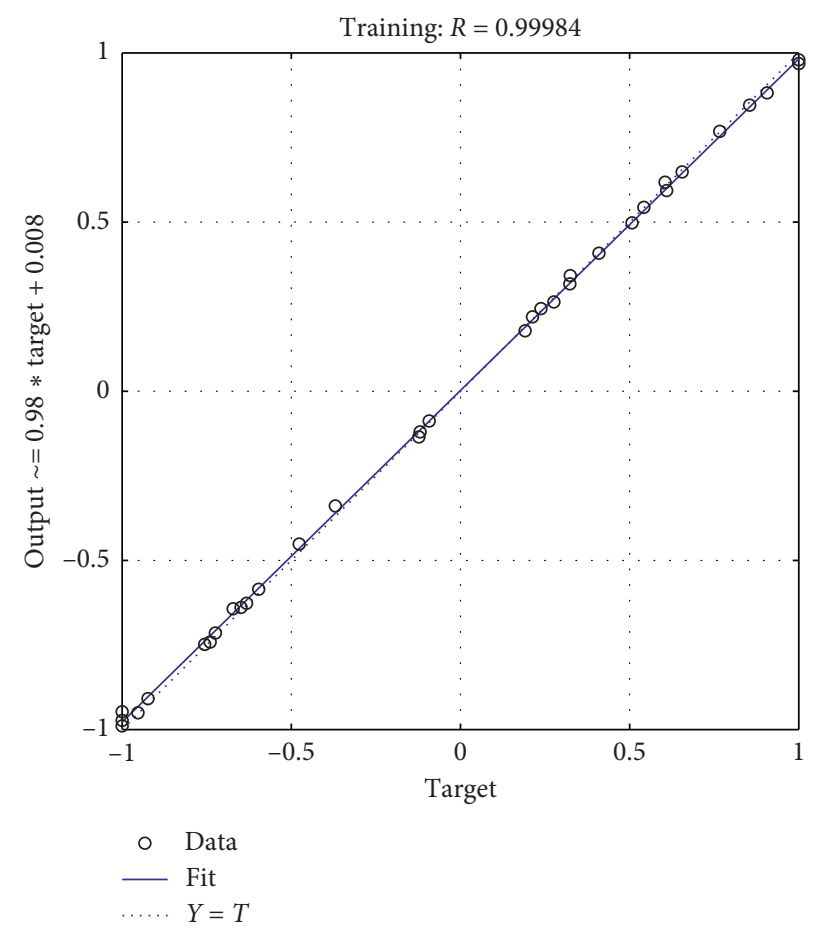

Figure 21: Training results.
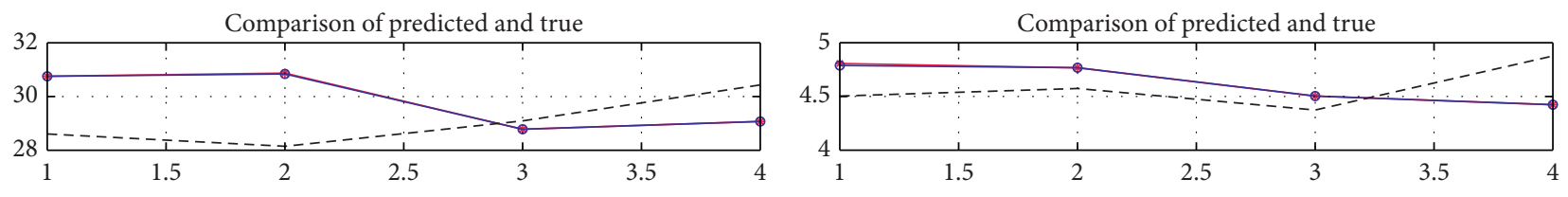

$\rightarrow$ Expected output

$\rightarrow$ Genetic algorithm optimization

- - - BP

$\rightarrow$ Expected output

$\rightarrow$ Genetic algorithm optimization

-- - BP

(a)

(b)

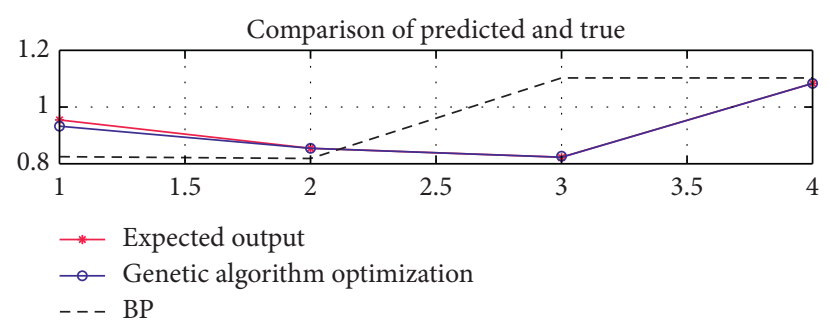

(c)

FIgURE 22: Comparison of predicted and experimental values.

on the neural network model established in the previous section and use genetic algorithm to optimize the process parameters [19].

\subsubsection{Design of Genetic Algorithm}

(1) Way of Encoding. The real number encoding was used and the chromosome was made up of the genes which were the order of the process parameters. The expression of chromosome was $X=\left[T, t_{t}, P, t_{p}\right]$. Before encoding, the range of process parameters was set, which was the constraint condition of the genes, as shown in Table 8.

(2) Function of Fitness. The optimization goal was to minimize the value of each evaluation indicator. A specific set of values were set so that the evaluation indicators were close but not equal. Therefore, the objective and fitness functions are, respectively, (30) and (31): 


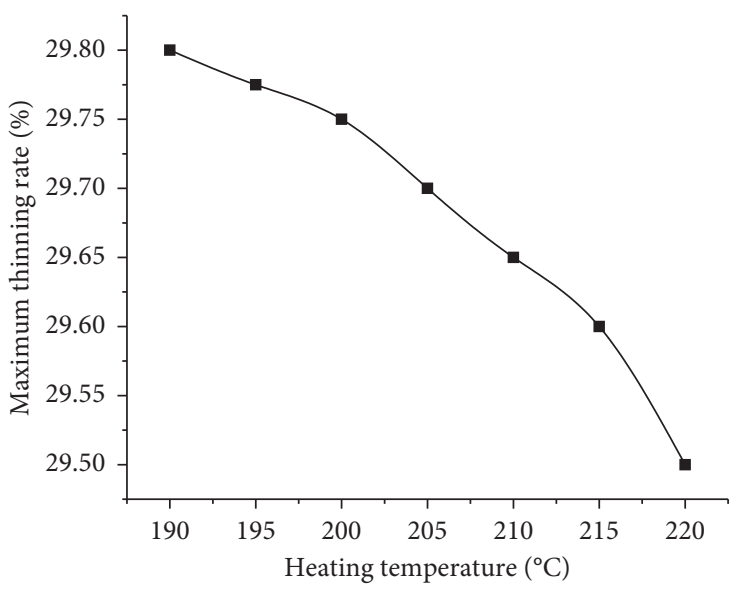

Maximum thinning rate

(a)

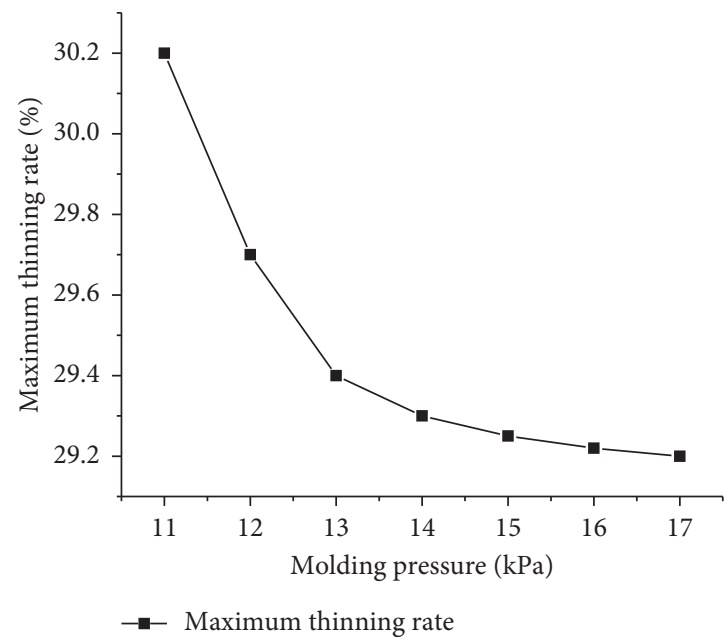

(c)

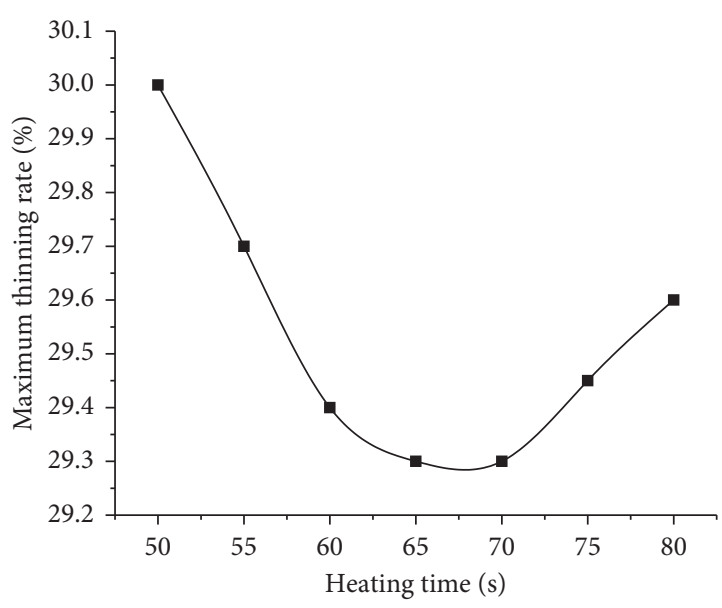

- Maximum thinning rate

(b)

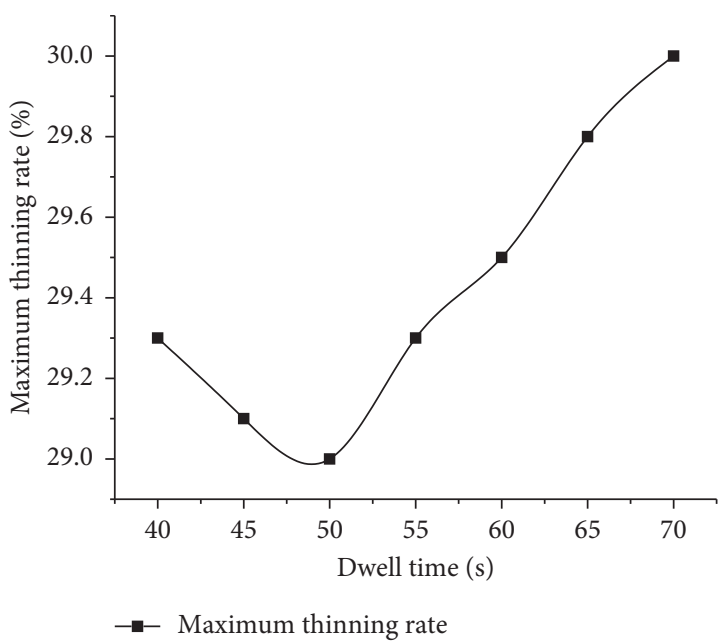

(d)

Figure 23: Trend of maximum thinning rate with process parameters. (a) Trend of maximum thinning rate with heating temperature. (b) Trend of maximum thinning rate with heating time. (c) Trend of maximum thinning rate with molding pressure. (d) Trend of maximum thinning rate with dwell time.

$$
\begin{aligned}
J & =\left(B^{\prime}-B\right)+\left(H^{\prime}-H\right)+\left(\eta^{\prime}-\eta\right), \\
\text { Fit } & =\frac{1}{(1+J)} .
\end{aligned}
$$

In the formulas, $B^{\prime}, H^{\prime}$, and $B^{\prime}$ are predicted values of maximum thinning rate, maximum thickening rate, and shrinkage rate; $B, H$, and $\eta$ are expected values of maximum thinning rate, maximum thickening rate, and shrinkage rate.

4.5.2. Realization of Optimization of Molding Process Parameters. The basic crossover and the adaptive crossover were combined and the adaptive mutation operator was improved. Population evolution parameters, $G=100, M=50$, and $R=0.7$, were set, and the probability of variation was set to 0.1 . The specific process is shown in Figure 26.

4.6. Optimization Results of Process Parameters Based on Genetic Algorithm. The expected target maximum thinning rate was $28 \%$, the maximum thickening rate was $43 \%$, and the shrinkage rate was $0.8 \%$ based on the optimal values of the existing evaluation standards. Through running programs multiple times, the optimal parameter combination was the heating temperature of $209^{\circ} \mathrm{C}$, the heating time of $62 \mathrm{~s}$, the molding pressure of $14 \mathrm{kPa}$, and the dwell time of $49 \mathrm{~s}$. The predicted evaluation indicators 


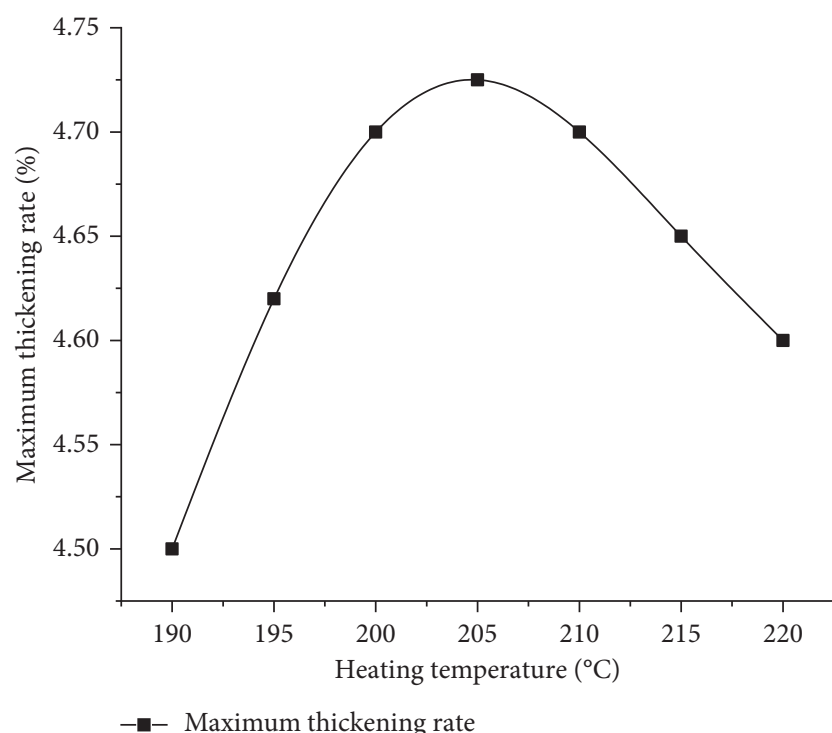

(a)

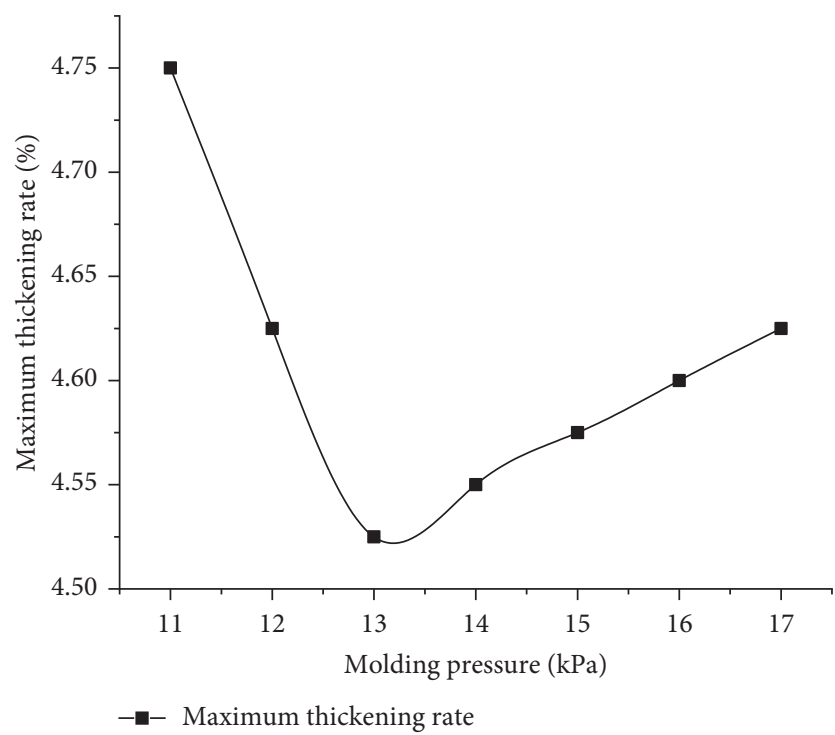

(c)

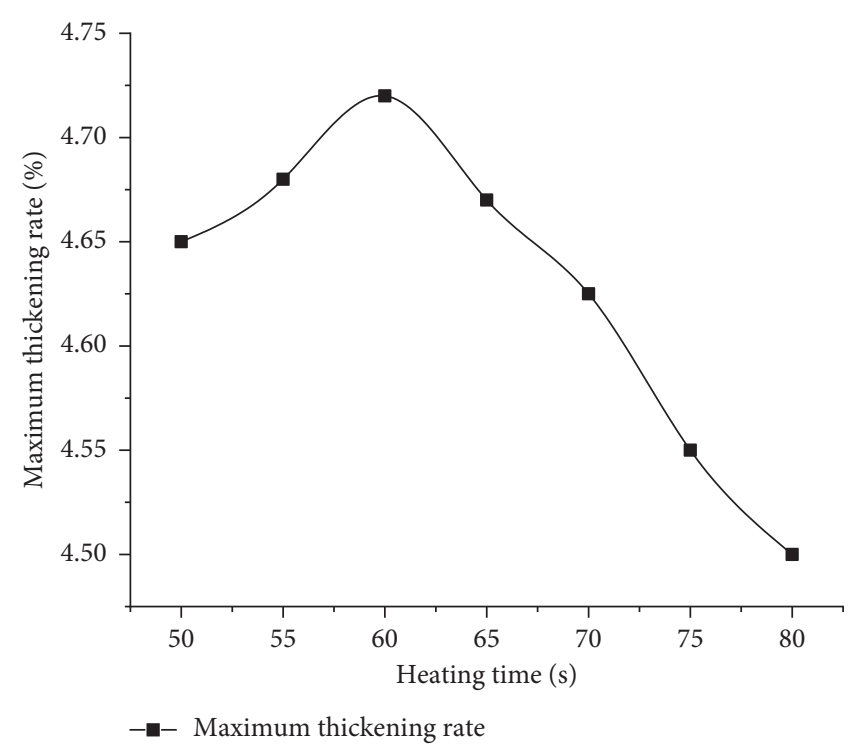

(b)

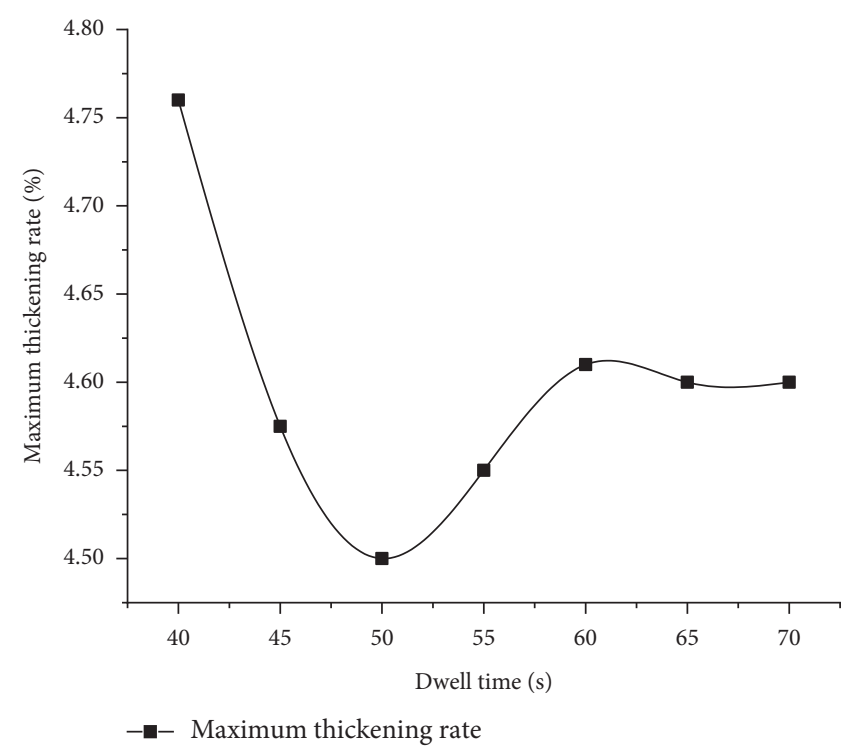

(d)

Figure 24: Trend of maximum thinning rate with process parameters. (a) Trend of maximum thickening rate with heating temperature. (b) Trend of maximum thickening rate with heating time. (c) Trend of maximum thickening rate with molding pressure. (d) Trend of maximum thickening rate with dwell time.

are the maximum thinning rate of $28.0880 \%$, the maximum thickness rate of $44.3264 \%$, and the shrink rate of $0.8901 \%$. These indicators showed that the molding quality was excellent. In the actual production process, the optimal parameters needed to be rounded; the heating temperature was $210^{\circ} \mathrm{C}$, the heating time was $60 \mathrm{~s}$, the molding pressure was $15 \mathrm{kPa}$, and the holding time was $49 \mathrm{~s}$. The results of genetic algorithm optimization are shown in Figure 27.

The process parameters were adjusted to the optimal process parameters, and two trunk trim panels were produced. The combination of the trunk trim panel and the sheet metal was checked with the gauge, and the maximum thinning rate, maximum thickness increasing rate, and shrinkage could be measured. The results are shown in Table 9. It can be seen from the evaluation indicator values that the trunk trim panel production guided by the optimal process parameters had the good quality and the trunk trim panel production guided by the genetic algorithm optimized by neural network had better accuracy. 


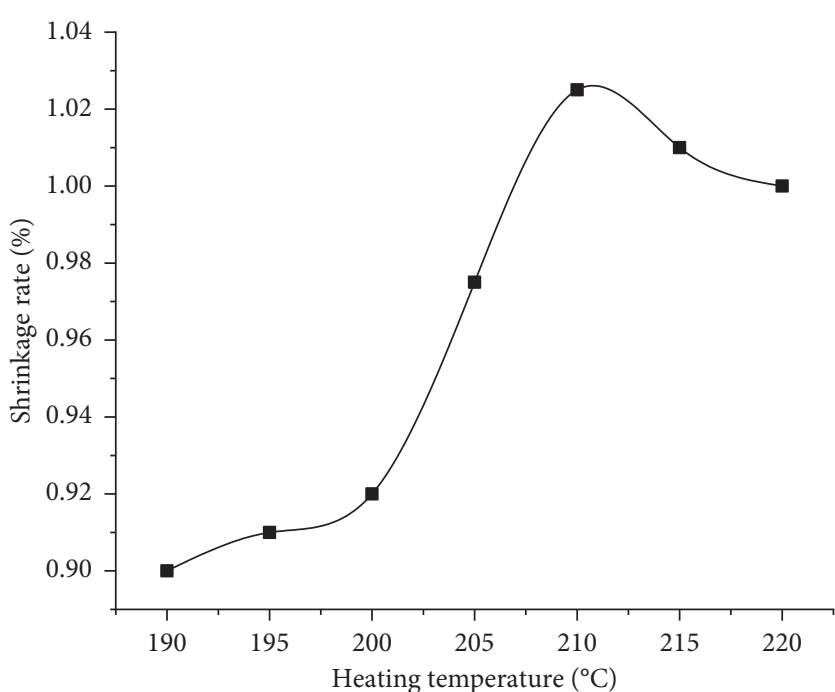

Shrinkage rate

(a)

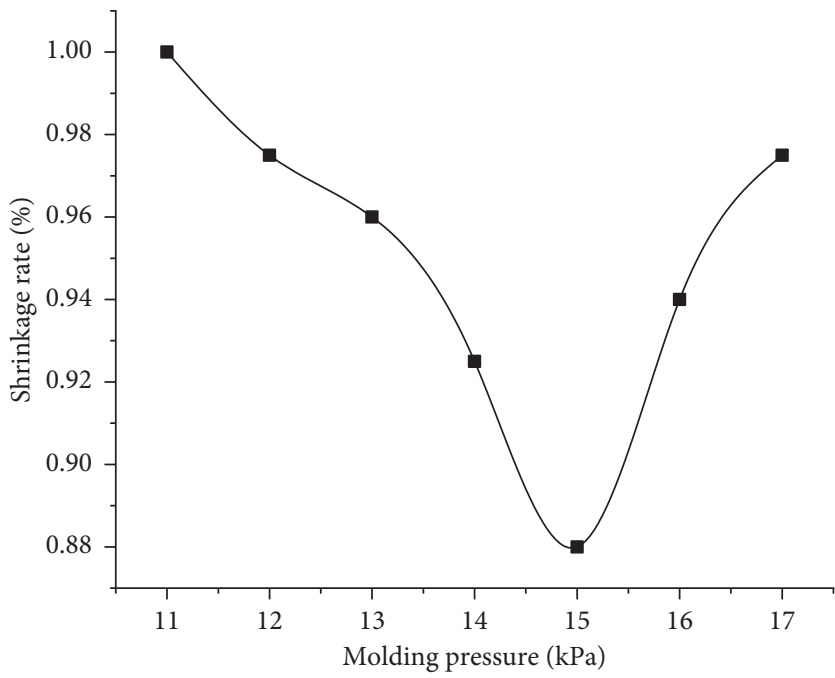

Shrinkage rate

(c)

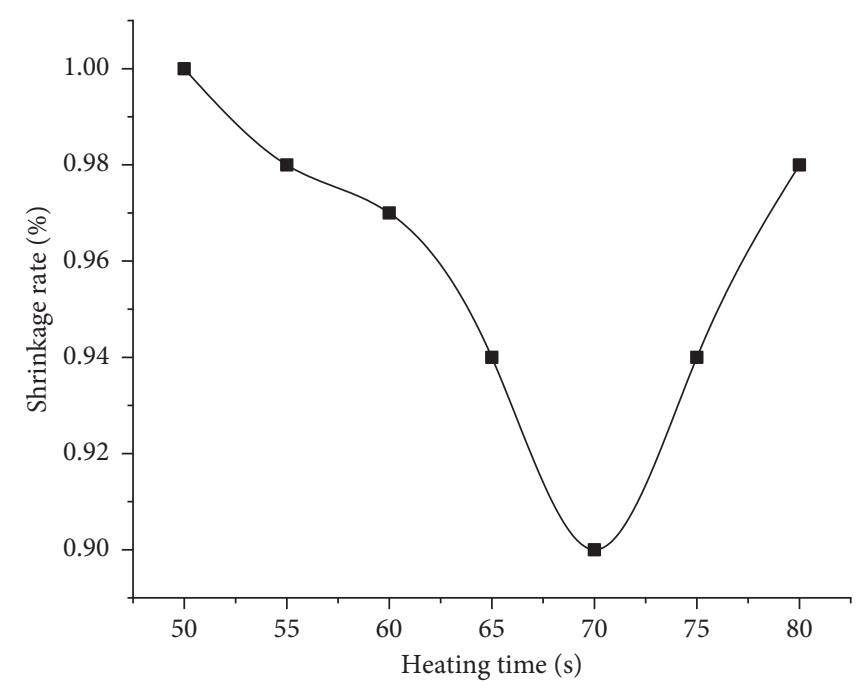

Shrinkage rate

(b)

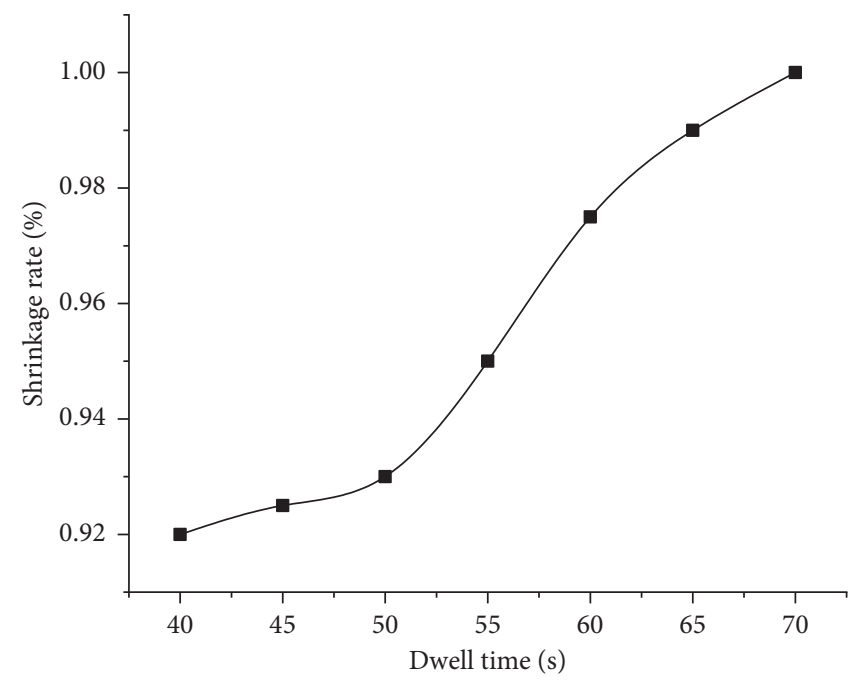

Shrinkage rate

FIgURE 25: Trend of maximum thinning rate with process parameters. (a) Trend of shrinkage rate with heating temperature. (b) Trend of shrinkage rate with heating time. (c) Trend of shrinkage rate with molding pressure. (d) Trend of shrinkage rate with dwell time.

TABLE 8: Value range process parameters.

\begin{tabular}{lr}
\hline Process parameters & Range \\
\hline Heating temperature $T\left({ }^{\circ} \mathrm{C}\right)$ & $190 \sim 220$ \\
Heating time $t_{t}(\mathrm{~s})$ & $50 \sim 80$ \\
Molding pressure $P(\mathrm{kPa})$ & $11 \sim 17$ \\
Compress time $t_{p}(\mathrm{~s})$ & $40 \sim 70$ \\
\hline
\end{tabular}

TABLE 9: Quality test of trunk trim panel.

\begin{tabular}{lccc}
\hline Serial number & Maximum thinning rate (\%) & Maximum thickening rate (\%) & Shrinkage $(\%)$ \\
\hline 1 & 28.18 & 4.40 & 0.83 \\
2 & 28.23 & 4.35 & 0.85 \\
\hline
\end{tabular}




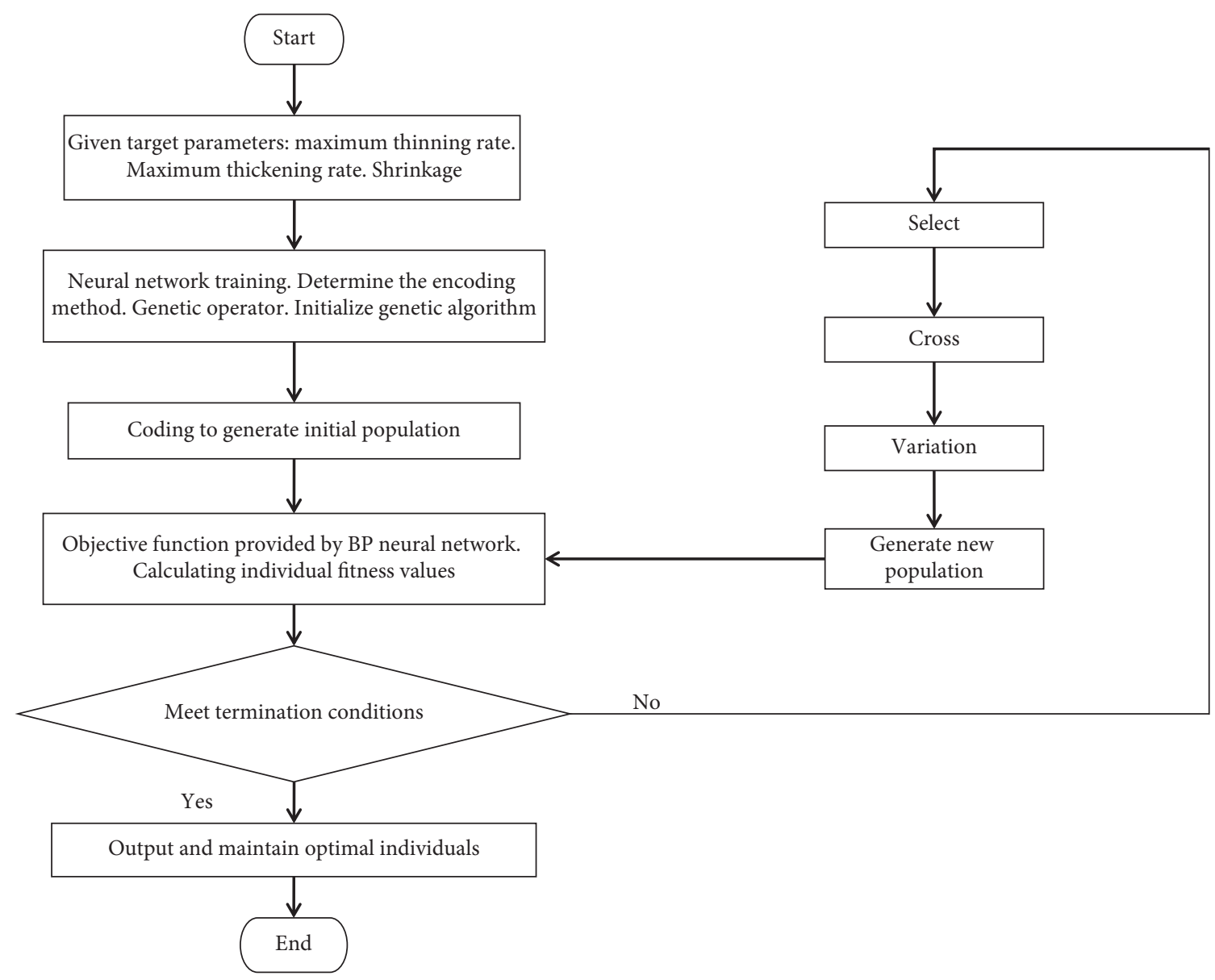

FIGURE 26: Flow chart of genetic algorithm to optimize molding parameters.

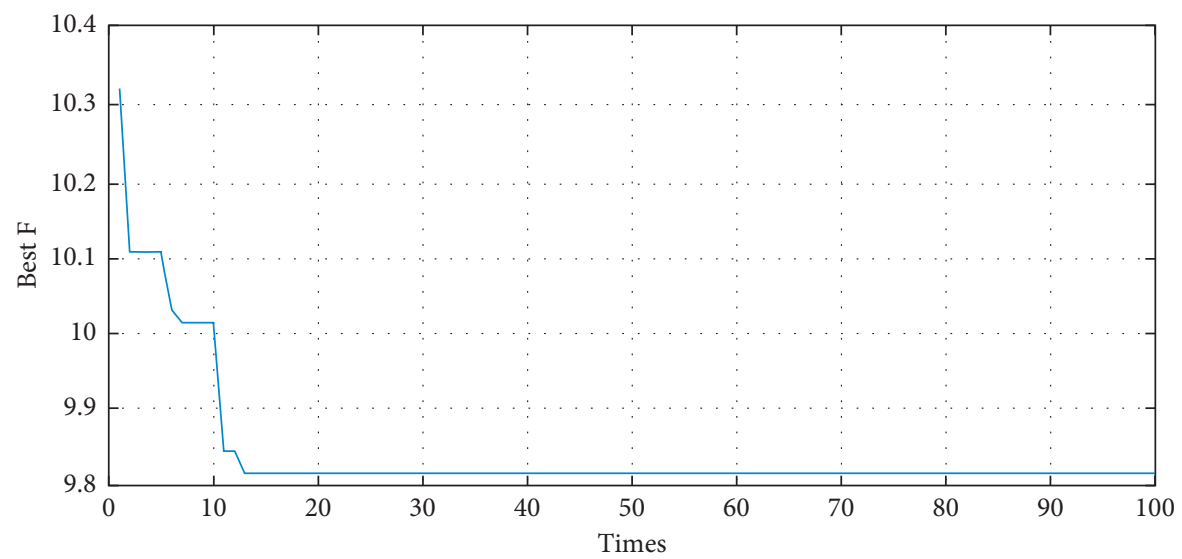

FIGURE 27: Results of genetic algorithm optimization.

\section{Conclusion and Prospect}

In this paper, by studying the process parameters affecting the trunk trim panel and conducting orthogonal experiments, the following results are obtained by optimizing the process parameters through genetic algorithm and BP neural network:
(1) Analyzing the compression molding of the trunk trim panel with mechanics theory, the theoretical calculation formula of the compression pressure of molding was deduced and the shrinkage rate of the trunk trim panel and the mold splitting were determined. The design of concave and convex molds and the compression molding of the trunk trim panel were completed. Thermal analyses were performed 
on the molding of the trunk trim panel, and a mold cooling system was designed.

(2) The evaluation index and process parameters were determined, the orthogonal experiment was completed, and the range analysis of the orthogonal experiment results was performed to obtain the influence trend of each level factor on the maximum thinning rate, maximum thickness rate, and shrinkage rate, as well as optimal combination of process parameters for evaluation indicators. When the heating temperature was $200^{\circ} \mathrm{C}$, the heating time was $70 \mathrm{~s}$, the holding pressure was $11 \mathrm{kPa}$, and the holding pressure time was $40 \mathrm{~s}$, the trunk trim panel could have a good comprehensive quality of three evaluation indicators.

(3) Normalization of training methods was improved, a BP neural network model for the optimization of the process parameters of the molding process of the trunk trim panel was established, and genetic algorithm was used to globally optimize the given process parameters to obtain the optimal combination of process parameters of the molding process of the trunk trim panel. When the heating temperature is $210^{\circ} \mathrm{C}$, the heating time is $60 \mathrm{~s}$, the molding pressure is $15 \mathrm{kPa}$, and the holding pressure time is $49 \mathrm{~s}$, the molding quality is excellent.

This article only uses the orthogonal test method and does not use the Taguchi method on the basis of further demonstration. It only has the experimental nature and does not demonstrate whether it can be further applied to the actual production of the enterprise. The following work will further demonstrate the desirability of the experimental results.

This article uses the method of optimizing the weights of the neural network and this method can compare two other optimization methods: optimization of structure and optimization of learning rules. Our team should choose a method with better optimization effect and learn a better neural network model to get more accurate optimization results.

The research process and ideas in this article will be applied to the following research on molding.

\section{Data Availability}

The data used to support the findings of this study are included within the article.

\section{Conflicts of Interest}

The authors declare that they have no conflicts of interest.

\section{Acknowledgments}

This article belongs to the major projects of the "Natural Science Foundation of Anhui Province Education Department (KJ2016SD05 and KJ2017ZD12)," the project of the "University Synergy Innovation Program of Anhui Province (GXXT-2019-004)," and the project of the "Teaching
Research Project of Anhui Education Department (2019jyxm0229)."

\section{References}

[1] Ü. Ağbulut and S. Sarıdemir, "A general view to converting fossil fuels to cleaner energy source by adding nanoparticles," International Journal of Ambient Energy, 2019.

[2] X. Wang, Q. Du, X. Liu, and Y. Xie, "Typical injection mold forming process simulation and mold deformation analysis," Machinery Design \& Manufacture, vol. 1, pp. 243-246, 2015.

[3] J. Xie, S. Wang, Z. Cui, and W. Jin, "Process optimization for compression molding of carbon fiber-reinforced thermosetting polymer," Materials, vol. 12, no. 15, 2019.

[4] K. Fujihara, Z.-M. Huang, S. Ramakrishna, and H. Hamada, "Influence of processing conditions on bending property of continuous carbon fiber reinforced PEEK composites," Composites Science and Technology, vol. 64, no. 16, pp. 2525-2534, 2004.

[5] X. B. Liang, Z.-Y. Cai, X. Zhang, and J.-X. Gao, "Plastic forming of the doubly curved surfaces of sandwich plates with bi-directionally trapezoidal cores of different sizes," ThinWalled Structures, vol. 146, 2020.

[6] S. Qin, X. Huang, and J. Wang, "Research on axisymmetrical deep drawing process based on radial double segmental blank," China Mechanical Engineering, vol. 22, no. 14, pp. 1741-1744, 2011.

[7] H. Cai, "Design and NC machining of injection mold for plastic shell based on UG and Moldflow," Plastics, vol. 44, no. 6, pp. 89-92, 2015.

[8] Ö. Erkan, M. Demetgül, B. Işik, and İ. N. Tansel, "Selection of optimal machining conditions for the composite materials by using Taguchi and GONNs," Measurement, vol. 48, 2014.

[9] C.-C. Su, W. Chien-Huan, and L. Bo-Ching, "Thermal and cure kinetics of epoxy molding compounds cured with thermal latency accelerators," Advances in Materials Science and Engineering, vol. 2013, Article ID 391267, 9 pages, 2013.

[10] Y. Zhu, H. Lu, and G. Dai, "Study on preheating technology for GMT thermoplastic sheet," China Plastics Industry, vol. 3, pp. 35-37, 2000.

[11] M.-J. Song, K. Kwon-Hee, and H. Seok-Kwan, "Simulationbased optimization of cure cycle of large area compression molding for LED silicone lens," Advances in Materials Science and Engineering, vol. 2015, Article ID 573076, 11 pages, 2015.

[12] M. Moayyedian and M. Ali, "Multi-objective optimization of injection molding process for determination of feasible moldability index," Procedia CIRP, vol. 84, 2019.

[13] Ü. Ağbulut, A. Mustafa, and S. Suat, "Prediction of performance, combustion and emission characteristics for a dual fuel diesel engine at varying injection pressures," Energy, pp. 517-536, 2013.

[14] C. Pan, W. Li, and D. Yang, "Optimization analysis of injection molding process of decorative plate based on orthogonal test method and neural network," Plastics, vol. 47, no. 3, pp. 92-97, 2018.

[15] Y. J. Lin and X. J. Chen, "BP neural network learning algorithm and its software implementation," Applied Mechanics and Materials, vol. 513-517, 2014.

[16] H. S. Wang, Y. N. Wang, and Y. C. Wang, "Cost estimation of plastic injection molding parts through integration of PSO and BP neural network," Expert Systems with Applications, vol. 40, no. 2, pp. 418-428, 2013.

[17] F. Yin, H. Mao, and H. Lin, "A hybrid of back propagation neural network and genetic algorithm for optimization of 
injection molding process parameters," Materials \& Design, vol. 32, no. 6, pp. 3457-3464, 2011.

[18] F. Yin, H. Mao, and Hua, "Back Propagation neural network modeling for warpage prediction and optimization of plastic products during injection molding," Materials \& Design, vol. 32, no. 4, pp. 1844-1850, 2011.

[19] Ö. Erkan, I. Birhan, A. Çiçek, and F. Kara, "Prediction of damage factor in end milling of glass fibre reinforced plastic composites using artificial neural network," Applied Composite Materials, vol. 20, no. 4, pp. 517-536, 2013. 